\title{
An Experimental Study of Self-Enforcing Coalitions
}

\author{
Karl Jandoc ${ }^{1, *}$ (1) and Ruben Juarez 2 (i) \\ 1 University of the Philippines School of Economics, Encarnación Hall, Osmeña cor. Guerrero Sts., Diliman, \\ Quezon City 1101, Philippines \\ 2 Department of Economics, University of Hawaii, 2424 Maile Way, Saunders Hall 542, Honolulu, \\ HI 96822, USA \\ * Correspondence: kljandoc@up.edu.ph
}

Received: 3 July 2019; Accepted: 30 July 2019; Published: 1 August 2019

\begin{abstract}
We study a model in which agents endowed with power compete for a divisible resource by forming coalitions with other agents. The coalition with the greatest power wins the resource and divides it among its members via proportional sharing. We conduct an economic experiment using this model to investigate possible behavioral factors that may explain deviations from theoretical predictions. The main findings show that agents display rational behavior when forming coalitions, especially when they know that a large proportion of their opponents play myopic strategies from the outset. Over time, however, agents learn to behave more strategically and even more rationally, thus enabling agents to display more of the behavior predicted by the coalition formation model with farsighted agents.
\end{abstract}

Keywords: coalition formation; power accumulation; self-enforcement; experiment

JEL Classification: C70; C91; D71

\section{Introduction}

The main economic rationale behind why agents cooperate strategically and form groups is that they can appropriate certain advantages unavailable to them if they acted on their own. In this framework, rational agents endogenously form coalitions, depending on the incentive structure or the environment they face. Recently, modeling how agents form coalitions in the face of very diverse environments has become a topic of active interest. An excellent introduction to the concepts in this literature is Ray [1].

In particular, a recent advance in the coalition formation literature introduces heterogeneous power for the agents and examines how its configuration in society affects the manner in which coalitions form endogenously. ${ }^{1}$ This has been motivated by real-world events ranging from political survival (Bueno de Mesquita et al. [2]; Tullock [3]; Acemoglu et al. [4]) to boardroom battles in business (Ward et al. [5]). Acemoglu, Egorov, and Sonin [4] (hereafter "AES") provide an important progress in examining power and how it affects how coalitions form. The coalition formation process of AES is framed in a dynamic context, where over time an agent evaluates whether to continue with the coalition in which he belongs, or whether to deviate to another one. The main problem AES tackles is to characterize the existence of a "stable" coalition and to describe the incentives by which the agents will choose to form this stable coalition.

1 Power is the ability to influence the behavior of other agents and could emanate from different sources, for instance political, military, or monetary. 
More specifically, AES provides a bargaining model where agents with different powers make proposals and respond to such proposals to try to form coalitions with sufficient power to win a prize over an indefinite period. An agent is randomly chosen to propose a coalition with some other set of agents in the society. Those agents being proposed to will respond by either voting "yes" or "no". If the combined power of those who voted "yes" is higher than those who voted "no" (plus the power of the agents outside the proposed coalition) then the proposed coalition will pass and will constitute a "winning" coalition. With each transition of the game where a proposed winning coalition is accepted by its members, agents outside this winning coalition are "killed" and are unable to participate in future time periods. The "ultimate ruling coalition" - the winning coalition that will be proposed and accepted forever without any further deviations, starting from a particular point in time-will win the prize and its members will divide this prize among themselves in proportion to their relative power inside this coalition. ${ }^{2}$ AES then show that the unique subgame perfect equilibrium of their bargaining process involves strategies that allow for an ultimate ruling coalition to form after one transition, with no intermediate coalitions forming. ${ }^{3}$

As a concrete example, imagine three agents in a society where one agent has power 20 (called "Agent 20"), another agent has power 35 ("Agent 35"), and another agent has power 45 ("Agent 45 "). Please note that no single agent has sufficient power to win, and so he must propose to at least one other agent that they form a "winning" coalition, in order for them to have at least $50 \%$ of the power in the society (a majority). Suppose Agent 35 was randomly selected to be a proposer and he proposed coalition $\{20,35\}$ to Agent 20. This coalition is winning, since the sum of their powers (55) is more than the remaining Agent 45 (that is, they have more than $50 \%$ of society's total power). Now 20 can either accept or reject this proposal. If he accepts, $\{20,35\}$ forms and Agent 45 is killed. In the next period, another proposer is selected, but this time only from Agents 20 or 35 . Agent 20 can only propose $\{20,35\}$, since he is not winning by himself. Agent 35 , however, can propose himself as a dictator. ${ }^{4}$ If that happens, $\{35\}$ will be the ultimate ruling coalition from this period onwards. Since Agent 20 is fully rational and farsighted, he will never agree to form $\{20,35\}$ and thus rejects this proposal when faced with it. Following this argument, no two-person coalition will ever form in this example. On the other hand, proposing the grand coalition $\{20,35,45\}$ is feasible, since it will never deviate into a two-person coalition, following the same logical process outlined above. Hence, this coalition is said to be "self-enforcing" or stable. In this simplified version of the AES model, farsighted agents know that if they propose a two-person coalition with a higher-powered agent, they will be killed in the future. Higher-powered agents, on the other hand, know they will be rejected by farsighted, lower-powered agents if a two-person coalition is proposed. Hence, the unique subgame perfect equilibrium strategy requires the proposal of the self-enforcing coalition $\{20,35,45\}$ and nothing else, while the responders would accept the self-enforcing coalition $\{20,35,45\}$, a two-person coalition if proposed by a lower-powered agent, and reject anything else. Playing these Subgame Perfect Nash Equilibrium (SPNE) strategies would allow the grand coalition $\{20,35,45\}$ to form at once. In this particular example, we can see clearly that if agents are farsighted, then an ultimate ruling coalition that is not a dictator will form.

2 AES's main stability concept, self-enforcement, requires that there will be no subcoalition of the winning coalition that will be powerful enough to encourage further deviations. Self-enforcement is a robustness property that ensures that the coalition that forms will never disintegrate thereafter. Another appealing axiom they use is rationality, which requires agents to pick the coalition that gives them their highest pay-off among self-enforcing coalitions. Rationality is related to immunity to group manipulations in models discussed by Bogomolnaia and Jackson [6], Ehlers [7], and Juarez [8].

3 Jandoc and Juarez [9] extend the analysis of Acemoglu et al. [4] to the case where power accumulates, as well as to the case when the prize is shared equally among the agents.

4 Here and in succeeding sections, we use the term dictator if an agent is able to deviate and form a singleton coalition. 


\subsection{Experimental Testing of the Theory}

Herein, we let subjects participate in a laboratory experiment to investigate whether the agents' actual behavior adheres to the theoretical predictions of the AES model. In this experiment, we play a version of the coalition formation model corresponding to the setting described in the example above. Employing an experimental approach is useful in this setting for two reasons. First, adopting a simplified version of the AES coalition formation model enables us to examine the extent to which agents' behavior deviates from the predictions of this model. While the AES coalition formation process (see Section 3) provides clear-cut predictions on what coalition will emerge starting from a society of agents with specific powers, it rests on the assumption that agents are farsighted and only care about their pay-off from self-enforcing coalitions. If agents are myopic, then it is possible that dictatorships will be more likely to form, since by trying to maximize immediate payoffs agents may fail to foresee that deviation into a non-self-enforcing coalition would lead to further deviations that may exclude them in the future. ${ }^{5}$ If the deviation is substantial, we can examine the agents' strategies to determine whether myopia has hindered them from attaining the model's prediction.

Second, we can determine whether agents are able to behave more rationally by increasing the incentives for them to do so or by gaining experience through time. The AES game is set up in such a way that the size of the resource has no bearing on the ultimate coalition that will form, since only the agents' relative payoffs matter. In real-world settings, however, stake size may affect behavior, because it could induce agents to behave more "cooperatively", since losing the pot entails a higher potential loss, or it could induce them to behave more selfishly, because winning the bigger pot entails a higher gain. Moreover, the AES model provides no scope for learning despite the dynamic nature of their game. In reality, though, boundedly rational agents may behave myopically at first but then learn to be strategic, if given enough experience playing the game. ${ }^{6}$

There are other possible behavioral explanations why agents may not conform to our coalition formation predictions. First, there are aspects of social preferences such as approval for pro-social behavior (LePine et al. [12]) that may affect the coalition formation process. As we will see in our experiment later, two-person coalitions (e.g., $\{20,45\})$ may form even if it is not in the best interest of the higher-powered agent (i.e., 45) because from society's point of view, it is "pro-social" to do so. Second, reputation effects signal to other lower power agents that they can be "trusted" not to propose a dictatorship when two-person coalitions are formed. Relatedly, agents may choose to display "reciprocity" (Charness and Rabin [13]). For instance, when an agent agrees to form a two-person coalition when he is the high-powered agent in the hopes that he will be repaid with the same behavior when he draws a low power in some future game. Third, fairness considerations could sustain coalitions that form outside AES predictions (Grüning and Peters [14]). If a higher-powered agent think it is "fair" to include a lower-powered agent in a two-person coalition, then a two-person coalition may form when proposed. We touch on some aspects of these issues in the succeeding sections.

5 We use myopia as the tendency of agents to choose earlier rewards over future ones. There are proposed explanations for why people choose short-term rewards. First, agents' time preference may exhibit hyperbolic discounting where future rewards are more heavily discounted the longer is the horizon (Frederick et al. [10]). Second, agents may exhibit imperfect forecasting where agents fail to judge or forecast the value of rewards that occurs further in time (Gabaix and Laibson [11]). This might happen, for instance, when agents lack the ability to properly backward induct. In this paper, we use the terms "myopic" and "shortsighted" interchangeably, and is meant to describe agents that prefer to form coalitions that may potentially reduce their future payoffs compared to playing the AES equilibrium strategies.

6 In the AES model, agents outside the winning coalition are killed and the surviving agents can therefore learn from observing past actions of agents that were killed. Indeed, with a large population, such inter-game learning can affect subsequent stages of the coalition formation game. In our experimental bargaining setup with three agents, however, there will be no scope for inter-game learning since the only feasible deviation is into a two-person coalition which will end in the subsequent round either as a dictator or a two-person coalition. Since we play the experiment repeatedly, we will mainly capture the effect of intra-game learning, or learning by playing many subsequent games. 
In summary, we used a laboratory experiment to address the following questions: Do agents form coalitions as the model predicts? If not, why does behavior deviate from prediction? Do myopia, learning, and stake size affect agents' decisions and the strategies they use?

\subsection{Overview of the Results}

Our experiment shows that the coalition formation equilibrium proposed by AES is not a perfect predictor of the actual coalitions that form. In our setting, the proportion of the grand coalitions that form almost never exceeds half of the total coalitions in every game. Over time, however, the proportion of grand coalitions forming tends to rise. Stake size helps slightly in increasing the proportion of grand coalitions forming. Examining the actions of the agents, we find a fairly regular pattern for proposals and responses. First, the proposed coalitions are conditional on a particular agent's power; for instance, agents who have low power (20) tend to propose the grand coalition, while agents assigned with higher power ( 35 or 45 ) tend to propose a two-person coalition, especially to the lower-powered agent (20), whereby they can obtain a higher share of the prize. Second, most of the decisions to accept or reject a proposed coalition are also contingent upon both an agent's drawn power and the coalition proposed. For example, almost everyone with power 45 accepts a proposed two-person coalition, while only about half of agents with power 20 accept this option. Moreover, almost all agents with power 20 accept a proposed grand coalition.

Put into a larger perspective, our results suggest that many agents exhibit behavior deviating from pure farsightedness and full rationality but learn to behave more strategically with enough experience of playing the coalition formation game. This suggests that elements of AES may be at work in the real world; hence, examining these behavioral factors in a strategic context may prove useful in developing future coalition formation models that will help us understand better how agents form groups in reality.

\section{Literature}

\subsection{Experiments on Coalition Formation}

Previous literature on experiments on coalition formation focused on testing the predictions of equilibrium concepts in cooperative game theory, subsequently expanding to test the predictions in bargaining models as well as in contests and tournaments. However, this strand of experimental literature does not explicitly feature differences in agents' power or influence within groups.

The earliest experiments on coalition formation were designed to test and compare solution concepts in cooperative game theory such as the core (Horowitz [15]) and the individually rational bargaining set (Rapoport and Kahan [16]). This literature also includes testing whether collective decision-making follows behavior predicted by the core (Fiorina and Plott [17]).

Along with the rise in the popularity of the bargaining approach to coalition formation (e.g., Baron and Ferejohn [18]) came experiments to test the theoretical predictions of these models. For instance, several papers attempted to implement the procedures in the Baron and Ferejohn model to test its predictions (McKelvey [19], Frechette et al. [20], Battaglini and Palfrey [21]).

More recently, Nash et al. [22] conducted an experiment to test a bargaining coalition formation game where players form coalitions by transferring bargaining rights to another player (the "agent"), who is then tasked to distribute payoffs to the coalition. While this paper highlights the tension between the incentive of players to keep a larger share of the resource and maintaining cooperation inside the coalition, it does not address the issue of dynamic coalition stability and the tension between myopic and farsighted payoffs.

There is also a growing body of literature on experiments relating to contests and tournaments. The theoretical literature of coalition formation in contests usually deal with the tension between how agents need to form groups to increase the probability of winning the contest prize and how features of the contest (e.g., the prize, cost of group formation, and the value of the coalition) affect 
the structure of the coalitions that will form (Sanchez-Pages [23]). Studies that used experiments to test the theoretical predictions of this literature include Herbst et al. [24] which examines moral hazard and endogenous alliance selection, whereby players choose which groups to form, and the effort expended in a contest against outsiders. There are also experimental studies that deal with how structures (players and prizes), spillovers, heterogeneity, and information affect group formation in contests, which is surveyed in Dechenaux et al. [25].

We believe our paper is the first to investigate the implications of heterogeneous power on the dynamic stability of coalitions. In this paper, we implement the procedural rules from the bargaining game of the AES model, and then we examine agents' strategies in the event that the outcome deviates from the theoretical prediction. ${ }^{7}$

\subsection{Learning and Experience}

Economic experiments usually control for the fact that agents will undergo a period of trial-and-error process in early phases of the experiment, either due to unfamiliarity with the rules of the game or unfamiliarity with the actions they are required to take. In the context of coalition formation experiments, repeated interactions of agents allow for learning and experience to improve the speed to which agreements are made and how payoffs increase for coalition members. In Merida-Campos and Willmott [27], agents repeatedly play a coalition formation game with pre-defined strategies for agents to be part of a winning coalition over several rounds. However, their approach is essentially static, and no learning is afforded even though agents repeatedly interact. In contrast, Chalkiadakis and Boutilier [28] used a Bayesian reinforcement learning model where agents learn about the types of individuals an agent is dealing with and allows him to decide whether to stay with his current coalition or to form coalitions with another set of agents. When a coalition forms, an agent can observe the value of the coalition. From this, the agents will update their beliefs about the other agents' types.

Outside the coalition formation literature, several models of learning have been developed to account for the possibility that agents will adapt their beliefs to past experience instead of reasoning strategically. These models show that agents have a high degree of myopia; however, Hyndman et al. [29] show through an experiment that economic agents actually rely on both adaptation and forward-looking behavior. Mengel [30], in the meantime, provides a learning model that ties together the two features of adaptability and forward-looking behavior. The model can provide explanations for the possibility of cooperation in finitely repeated games.

While there are several ways to model the dynamic and adaptive process of learning, we take a straightforward approach by simply enumerating the strategies employed over the progress of the game, as well as the types of coalitions that will form in early and late games.

\subsection{Stake Size}

One of the unresolved issues in experiments in coalition formation (or economic experiments in general) is whether representative (small) experimental stakes translate into behavior that reflect situations in the real world. Harrison and List [31] provide an excellent review of varying stakes in economic experiments-the question here is whether they are non-trivial enough to induce agents to reveal their true behavior. To make the stakes appear more substantial, several experiments have been conducted in developing countries where participants are poor enough to make the stakes more salient; for instance, Slonim and Roth [32] ran their experiments in the Slovak Republic, Kachelmeier and Shehata [33] in China, and Cameron [34] in Indonesia, among others. The stakes in these experiments equaled roughly 62.5 hours of work in Slovakia or three times the monthly expenditure of the average participant in Indonesia. The effect was somewhat mixed, in that some high-stakes cases, such as the

7 Tremewan and Vanberg [26] point out that if the outcome from these experiments deviates from theoretical predictions, failure will emanate from behavioral rather than from procedural assumptions. 
Slovak Republic study, induced different behavior to that obtained with lower stakes, while in the Indonesian study it did not do so.

In this paper, we increase the stake size into some games and examine the coalitions that form as a result. In some games, we increase the stake from $\$ 5$ to $\$ 50$, while in others we increase only from $\$ 5$ to $\$ 20$.

The rest of this paper is organized as follows: Section 3 describes the important elements of the theory behind the coalition formation game we conduct in the laboratory. Section 4 describes the design of the experiment. Section 5 discusses the results of the experiment and Section 6 concludes.

\section{Theoretical Considerations}

Following AES, a set $N=\{1, \ldots, n\}$ of initial agents is endowed with powers $\pi=\left[\pi_{1}, \ldots, \pi_{n}\right]$, respectively. A coalition $S$ is a subset of $N$, i.e., $S \subseteq N$. The sets of coalitions are all possible subsets of $N$, denoted by $2^{N}$. A coalition formation game is a pair $(S, \pi)$, where $S \subseteq N$ and $\pi \in \mathbb{R}_{+}^{S}$. We assume that power is additive, i.e., the power of coalition $S$ is the sum of all powers of the agents inside the coalition, $\pi(S)=\sum_{i \in S} \pi_{i}{ }^{8}$ The set of winning coalitions is given by $W_{(T, \pi)}=\{S \subset T \mid \pi(S)>\pi(T \backslash S)\}$.

We assume that the agents divide a prize (pot) $I$ by a fixed sharing rule. If the agent is part of the final coalition $S$, then his share is proportional to his power $S$, i.e., $\xi_{i}(S, \pi)=\frac{\pi_{i}}{\pi(S)} I$ if $i \in S$. If the agent is not part of the final coalition, his pay-off is $\xi_{i}(S, \pi)=0$.

We have the following extensive form of the game $(N, \pi)$ : Stage $j$ of the game starts with coalition $N_{j}$. We define the proposal level $q$ as the number of times a proposer has been chosen within a stage. The stage game proceeds as follows:

1. Nature picks a proposer agent $a_{j, q} \in N_{j}$ for $q=1$.

2. Agent $a_{j, q}$ proposes a winning coalition $P_{j, q} \in W_{\left(N_{j}, \pi_{N_{j}}\right)}$, such that $a_{j, q} \in P_{j, q}$.

3. Agents vote yes or no regarding forming coalition $P_{j, q}$. The vote of the proposing agent $a_{j, q}$ is recorded as yes. The votes of the agents in $N_{j} \backslash P_{j, q}$, who are not part of the proposed coalition, are recorded as no. The agents in $P_{j, q} \backslash\left\{a_{j, q}\right\}$ vote sequentially following a random ordering thereof. If the agents who voted yes form a winning coalition in $W_{\left(N_{j}, \pi_{N_{j}}\right)}$, then proceed to Step 4; otherwise, proceed to Step 5.

4. If $P_{j, q}=N_{j}$, proceed to Step 6. If not, players from $N_{j} \backslash P_{j, q}$ are eliminated and the game reverts back to Step 1 with $N_{j+1}=P_{j, q}$ (and $j$ increases by 1 ).

5. If $q<\left|N_{j}\right|$, the next agenda setter $a_{j, q+1} \in N_{j}$ is picked randomly from among those in $N_{j}$ who have not yet proposed at this stage, and the game proceeds to Step 2 with $q$ increased by 1 . If $q=\left|N_{j}\right|$, the game proceeds to step 6 .

6. $\quad N_{j}$ becomes the ruling coalition, where each agent $i \in N_{j}$ receives pay-off $\xi_{i}\left(N_{j}, \pi_{N_{j}}\right)$.

The major result of AES can now be stated, and the proof found in Acemoglu et al. [4].

Proposition 1. For the bargaining procedure just described, there exists a pure strategy profile that constitutes a unique subgame perfect equilibrium and leads to an ultimate ruling coalition in at most one transition. ${ }^{9}$

Intuition is quite clear with the help of the example in Section 1. To reiterate, a farsighted, lower-powered agent knows that if he proposes a two-person coalition to a higher-powered agent, he will be killed, while higher-powered agents know that if they propose a two-person coalition to

8 It is common to assume to restrict the game $(X, \pi)$ such that the power profile $\pi$ has no ties in the power of any two coalitions; that is, $\pi(S) \neq \pi(T)$ for any $S, T \subset X$. Please note that the games that do not satisfy this condition has a Lebesgue measure equal to zero, so this is a weak condition (See Jandoc and Juarez [9], Acemoglu et al. [4]).

9 The pay-off in AES assumes an arbitrarily small cost that is interpreted as the cost of eliminating some of the players from the coalition or as a cost in organizing new coalitions. 
a farsighted, lower-powered agent, they will be rejected. Hence, on the equilibrium path only the self-enforcing grand coalition $\{20,35,45\}$ will be proposed, and the same coalition will be the only one accepted. Off the equilibrium path, however, higher-powered agents will accept a two-person coalition from a lower-powered agent. Playing these strategies would allow a self-enforcing coalition to be the ultimate ruling coalition in one transition, without forming any intermediate coalitions. ${ }^{10}$

\section{Experimental Design}

We consider a very simple implementation of the game procedures described in the previous section. In this experiment, our society is composed of three agents who are endowed with powers 20,35, or 45-as in the example in Section $1 .{ }^{11}$ As with the stages of the game above, we follow the steps below:

1. An agent is chosen randomly to be the proposer, and he proposes to form a winning coalition.

2. Agents sequentially vote yes or no on whether to join the proposed coalition. We assume that the proposer votes yes and the agents outside the proposed coalition vote no.

3. A coalition passes if the players who voted yes have over $50 \%$ of the power of the current coalition.

4. If a coalition passes, the game is repeated but only with the agents inside this passed coalition.

5. If the coalition fails, a new proposer is chosen randomly, and the game begins again.

6. The game ends if one of the following three cases happens:

- if no coalition is passed after everyone in the remaining coalition has been given a chance to propose. In this case, the remaining coalition is implemented, and the pot is divided in proportion to their power.

- if a dictator (unique agent) is left in the game. In this case, the dictator earns the full pot of money.

- if the two-person coalition is proposed and accepted by the two agents inside it. In this case, the two-person coalition is implemented and the pot is divided in proportion to their power.

- if the current grand coalition is proposed and unanimously accepted. In this case, the current grand coalition is implemented, and the pot is divided in proportion to their power.

In AES, it is the case that the first stage coalition is the grand coalition, i.e., $N_{1}=N$. The game ends whenever three things happen. First, there will be disagreements about all proposals after everyone has the chance to propose at a particular stage. For instance, if at the first stage everyone was given the chance to propose a coalition $(q=N$ in Section 3$)$ but all proposals were rejected, then the ruling coalition will be the grand coalition. This corresponds to the first termination rule in our experiment. Second, the game ends when in some future stage of the bargaining process, one player will have sufficiently high power to propose himself to be the dictator. In the notation of Section 3, $\left|P_{j+k}\right|=1$ for some future stage $k$. This captures the second termination rule in our experiment. Third, everyone proposed and accepts the same coalition at some stage. In the notation of Section $3, P_{j}=P_{j+1}=\cdots=P_{j+k}=N_{j}$ at some stage $j$ and $k=\left|N_{j}\right|$. This corresponds to the last two termination rules of our experiment.

10 While our paper focuses on testing the game proposed by AES, where the determination of the ruling coalition is done sequentially, we note that this assumption is strong and comes with limitations, such as the larger information-exchange needed for the determination of a ruling coalition and applicability to real-world events (e.g., elections or battles in business), where the selection of the ruling coalition is often done simultaneously. A natural extension not studied in our paper is the determination of the equilibrium and its testing for simultaneous versions of the AES's game.

11 We note that the determination of the self-enforcing coalition is very robust to the selection of power. In particular, for a three-agent society, unless one agent is a dictator, or two agents have each exactly $50 \%$ power, the only possible self-enforcing coalition is the grand coalition. 
Under AES's theory, if all agents are farsighted, no coalition of size two will be proposed or accepted on the equilibrium path. Off the equilibrium path, however, a higher-powered agent will accept a two-person coalition if proposed by a lower-powered agent. Hence, in this game the unique SPNE strategy is to propose only the grand coalition, accept the grand coalition $\{20,35,45\}$, if proposed, accept a two-person-coalition with a lower-powered agent, if proposed, and reject anything else. The unique outcome under the SPNE is the grand coalition $\{20,35,45\}$ forming.

We developed our own software to implement the games. The left panel of Figure 1 is a screenshot of the proposal stage, and on this screen the available information includes the agent's power, other agents' power and their order of proposal, the current turn, the proposed coalition, the pot, the coalitions available for proposal (i.e., those with sufficient power to win), and the corresponding payoffs of each agent in any potentially proposed coalition (if the proposed coalition becomes the ultimate ruling coalition). The randomly chosen agent then must propose one coalition to the other agents in the game.
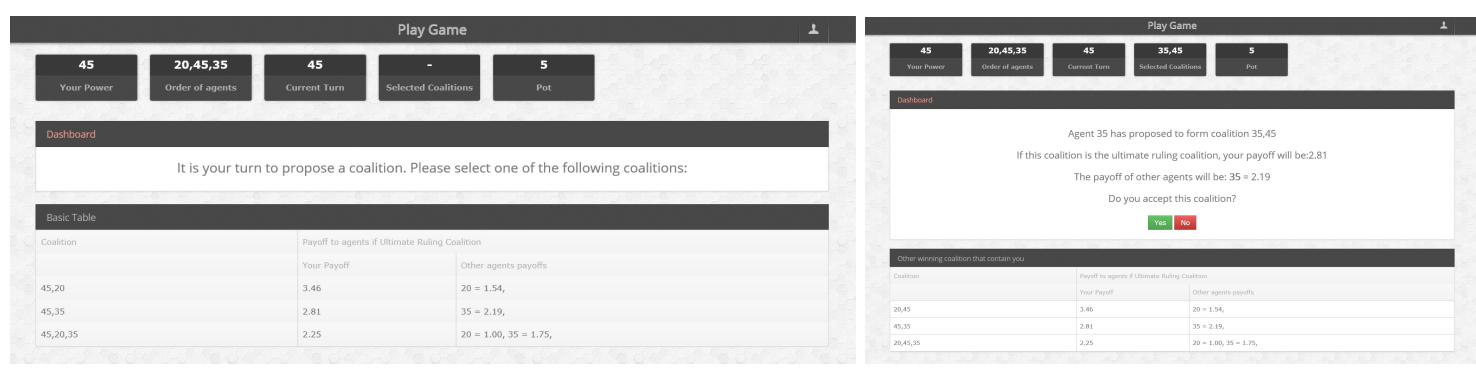

Figure 1. A screenshot of the proposal (left panel) and response stage (right panel).

Once a proposer has signaled his proposed coalitions, the other agents who are part of this proposed coalition move to the response stage and are shown a screen similar to the right panel of Figure 1. On this screen, the available information includes the agent's power, other agents' power, the pot (in dollar terms), the selected proposed coalition, the voting screen, other winning coalitions not chosen for proposal, and the corresponding payoffs of each agent. ${ }^{12}$ The agent then votes "yes" or "no" to the proposed coalition. The subsequent stages follow the same procedures until a final coalition passes.

In this experiment, the participants are undergraduate students from the University of Hawaii and were recruited via ORSEE (Greiner [35]). Subjects were allowed to participate in only one session in this experiment, but they may have had some prior experience with other non-related experiments. They were shown a video of the instructions and given an online quiz to test how they understood the instructions. ${ }^{13}$

To allow for learning in each session, the participants played up to 15 games with random re-matching. In each game they will be randomly assigned with equal probability to a starting power of 20,35, or 45 . We designated the first two games as "practice", where no subject would be paid. After these practice games, the subjects split a $\$ 5$ pot in each of the "paid" games played. ${ }^{14}$ We paid the subjects the actual amount that they won for all the paid games. To investigate the effect of increasing

12 Please note that this screen is only viewed by those agents included in the proposed coalition. If they are not part of the proposed coalition, their vote is an automatic "No" and they must wait to see whether the proposed coalition passes or fails. If the proposed coalition passes, then they must wait until the game ends.

13 The instructions can be viewed here: https://www.youtube.com/watch?v=ECl6kXPYyh8. Appendix A provides screenshots of the instructions and the quiz.

14 The players' payoffs are in real money (US dollars) to make the amount more salient as has been done in the literature on high-stake games, e.g., Cameron [34]. 
stakes, in some sessions we offered $\$ 20$ or $\$ 50$ in the last game. ${ }^{15}$ In total, we ran five sessions with \$50 final games, three sessions with \$20 final games, and three sessions with \$5 final games. Table 1 presents a summary of the experimental sessions. We held 11 sessions, and in each one we conducted up to 15 games.

Table 1. Summary of experimental sessions.

\begin{tabular}{cccc}
\hline Session Date & $\begin{array}{c}\text { Number of Games } \\
\text { per Session }\end{array}$ & Number of Subjects & Last Game Stake \\
\hline Low-stake sessions & 14 & 15 & $\$ 5$ \\
6 May 2014 & 14 & 15 & $\$ 5$ \\
4 February 2015 & 14 & 12 & $\$ 5$ \\
5 February 2015 & & & $\$ 20$ \\
\hline Medium-stake sessions & 14 & 12 & $\$ 20$ \\
6 May 2014 & 14 & 12 & $\$ 20$ \\
7 May 2014 & 14 & 12 & $\$ 50$ \\
6 June 2014 & & & $\$ 50$ \\
\hline High-stake sessions & 15 & 9 & $\$ 50$ \\
5 June 2014 & 15 & 9 & $\$ 50$ \\
23 June 2014 & 15 & 6 & $\$ 50$ \\
24 June 2014 & 14 & 15 & 15 \\
4 February 2015 & 14 & 15 & \\
5 February 2015 & 14 & & \\
\hline
\end{tabular}

Note: Total number of sessions is 11 . Total number of group games is 624 (column 2 times one third of column 3 and getting the sum). The first two games per session are designated as practice games. There are 132 total participants.

\section{Results}

There were a total of 132 participants and 624 group games in our experiment. Out of 624 group games, 536 games were paid, while 88 were practice games. Our analysis only covers the paid games in all sessions, i.e., we do not include the first two practice games. In this section, we present our key results for the types of coalitions that formed, and Section 5.1 presents an analysis of the strategies employed by the agents.

Observation 1. Very few grand coalitions form compared to the proportion of singletons (a dictatorship) during the early games of the experiment. However, the proportion of grand coalitions significantly increases in later games.

Considering all games, Figure 2 suggests that very few grand coalitions form, which does not seem to accord with the model's prediction where the grand coalition $\{20,35,45\}$ should always form. ${ }^{16}$ Taking all sessions together, there is no game in which the proportion of grand coalitions forming exceeds $50 \%$. In contrast, during the first few games, the proportion of singletons never goes below 50\%, which indicates that the AES model is a weak predictor of the coalitions that will form. In the following we examine some factors that may induce behavior that will move the results closer to the model's predictions.

In Figure 2, we also note that the proportion of grand coalitions steadily increases while that of singletons decreases. At the very end of the sessions, about half of the formed coalitions are grand coalitions, which suggests that the more agents learn how the game works, the more they tend to

15 We announced the stake prior to the start for each of these final games regardless whether it was a high stake (i.e., $\$ 20$ or $\$ 50$ ) or a low stake (i.e., \$5). We implemented the change in stakes in the last round to ensure that agents have learned the game sufficiently and any change in behavior would be purely attributed to the stake.

16 There are only 3 out of a possible 624 group games in which the grand coalition forms because all agents rejected every proposal made. 
implement the grand coalition. The proportion of two-person coalition-forming remains relatively steady throughout the games, except for the final game, where the proportion increases to $40 \%$.

In this paper, we designated games 9 onwards as games in "late" periods, where we suppose that the subjects have gained some knowledge of the experiment. The first set of bars in Figure 3 shows the mean proportion of grand coalitions forming in early games (games 3-8) and late games (games 9 onwards) in the different sessions. The mean proportion of grand coalitions in late games is around $40 \%$, while the mean proportion for early games is only $30 \%$. This difference is statistically significant, using sessions as the unit of observation ( $p$-value $=0.013$, Wilcoxon signed rank test).

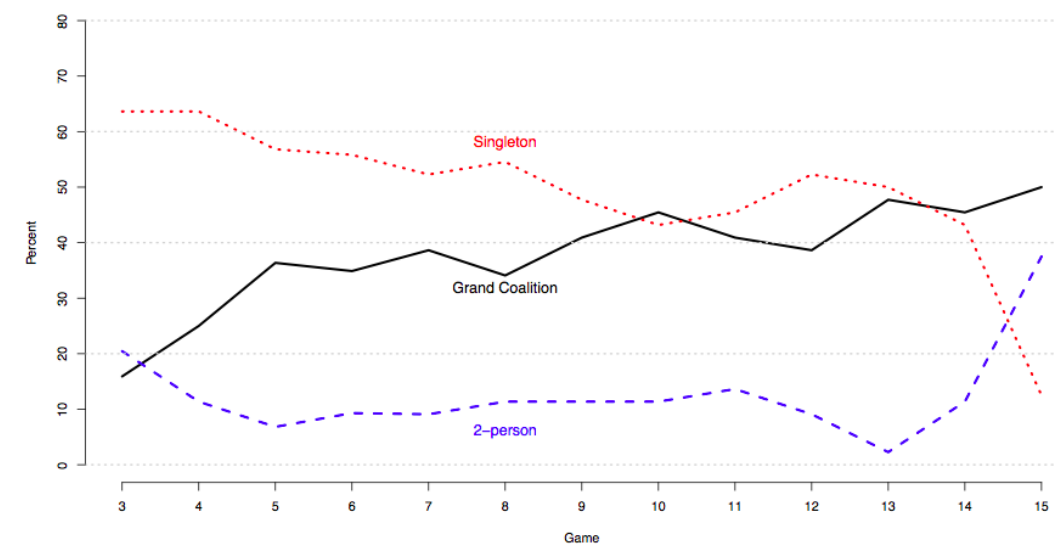

Figure 2. Percentage of final coalitions through games, by type. The percentages are computed over all sessions per game.
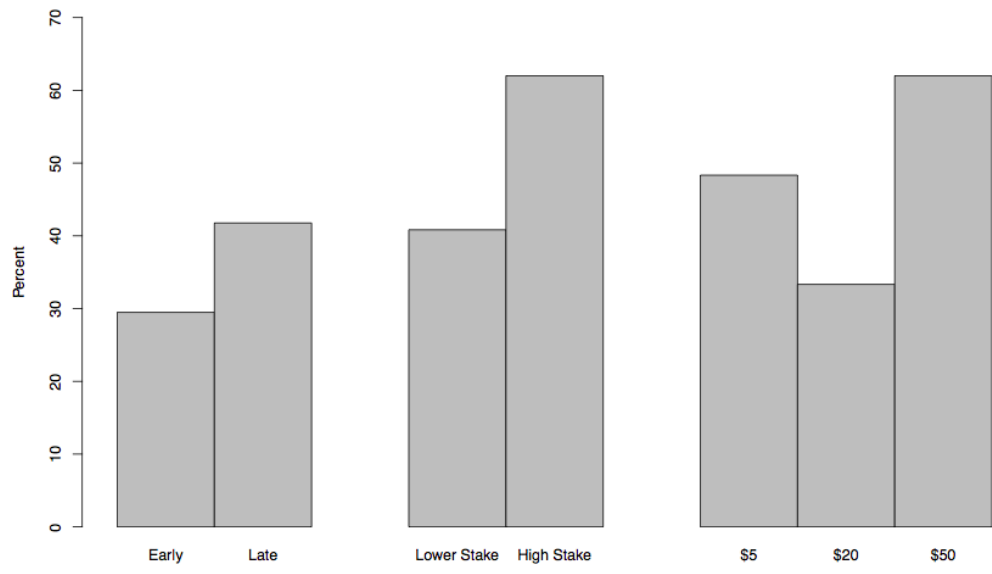

Figure 3. Percentage of grand coalitions forming, by time period and last game stake. The percentages are computed over all sessions. For instance, the bar for "Early" gives the proportion of formed grand coalitions on early games over all possible types of coalitions formed in these games.

The next set of results shows the effect of higher stakes.

Observation 2. The difference in the proportion of grand coalitions in high stakes versus low and medium stakes is substantial and significant.

The middle and rightmost sets of bars in Figure 3 show the percentage of grand coalition formation in the last game of the sessions by stake. In the rightmost set of bars, we see that when agents are offered a pot of $\$ 50$, close to $70 \%$ of coalitions that form are grand coalitions. However, when the pot is only $\$ 20$, about $30 \%$ of the coalitions are grand, which is lower than the proportion of grand coalitions in the low-stake games. In the middle set of bars in Figure 3, we lump together the $\$ 20$ and $\$ 5$ into the lower-stakes treatment and calculate the proportion of grand coalitions to total formed 
coalitions in the last game of the sessions. Using the sessions as the unit of observations, we see that the differences between the proportion of grand coalitions forming in the low and high stakes are substantial ( $40 \%$ vs. $62 \%$, respectively) but not statistically significant ( $p$-value $=0.26$, Mann-Whitney test). We also test the differences in mean proportions of grand coalitions forming for the last game vs. the late games (except the last) for both the lower stakes and the higher stakes. Differences in the proportion of grand coalitions forming in the last game vs. late games for lower stakes are statistically insignificant, using sessions as the unit of observation ( $p$-value $>0.10$, Wilcoxon signed rank test). For the high-stake games, this difference is statistically significant ( $p$-value $=0.10$, Wilcoxon signed rank test).

To provide an alternative (higher-powered) test to determine the effect of stakes on the formation of grand coalitions, we use a logit model (Table 2) with specifications that include late games as the sole control, stakes as the sole control, late games and stakes together, and a specification with session-fixed effects. ${ }^{17}$ We find that the coefficients of the $\$ 50$-stake games are robustly positive and statistically significant, showing that increasing the stake size substantially will have a positive effect on the propensity of agents to form grand coalitions. The runs with the stakes have substantially lower AIC compared to alternative models that omit them, for instance, the AIC for Specification 5 (744.041) is lower than the AIC in Specification 3 (745.057), suggesting that stakes matter in predicting the formation of grand coalitions. In the same Table, the Wald tests suggest that the there is no statistical difference between the effect of the $\$ 5$ stake vs. $\$ 20$ stake. These results reflect to some extent the results in the literature where relatively higher stakes are more salient to induce fairer outcomes (e.g., Slonim and Roth [32]).

\subsection{Analysis of Strategies}

With such low proportions of grand coalitions forming, it would be instructive to examine the strategies employed by the players. To flesh out the actions that our subjects employ, we now look at both the proposal and the response stages in the first round of every game, i.e., we look at the proposals and the responses of each agent every time a new game starts. Limiting our analysis on the first round of every game does away with the complications brought about by intra-game history, and will simplify our analysis. ${ }^{18}$

Observation 3. The proposed coalition is dependent on an agent's power draw. The lower-powered agent (20) proposes the grand coalition more frequently, whereas the higher-powered agents (35 and 45) propose a two-person coalition more frequently with the agent with the lowest power (20). This is consistent with agents playing their empirical best response, which maximizes their expected pay-off given the presence of myopic players.

Table 3 shows the percentage of proposed coalitions by power. ${ }^{19}$ While the model predicts that the grand coalition $\{20,35,45\}$ is proposed regardless of the drawn power of the agent proposing, it seems that agents propose coalitions that benefit them in the short term. For instance, for agents that have drawn powers 35 and 45 , a large proportion propose a coalition with the agent with the lowest power, i.e., Agent 20. About 73\% of proposals for players who draw power 35 is the coalition $\{20,35\}$, and $40 \%$ of proposals of agents who have drawn power 45 is $\{20,45\}$. On the other hand, we see that if an agent draws power 20 , he proposes the grand coalition $60 \%$ of the time. About $34 \%$ of the time, the power-20 agent proposes a two-person coalition with agent 35 .

17 We also include a specification where we define the late games to exclude the last game of each session.

18 However, it is also instructive to examine proposals after a deviation to a two-person coalition if it is part of a person's empirical best response strategy. This we do in Section 5.2.

19 Please note that there are no singleton coalitions in Table 3 because agents do not have sufficient power to propose themselves at the start of every game. 
Table 2. Probability of a grand coalition-forming

\begin{tabular}{|c|c|c|c|c|c|c|}
\hline & \multicolumn{6}{|c|}{ Dependent Variable: } \\
\hline & \multicolumn{6}{|c|}{ Grand Coalition Formed = 1} \\
\hline & (1) & $(2)$ & (3) & (4) & (5) & (6) \\
\hline Late Games & $\begin{array}{c}0.832 * * * \\
(0.159)\end{array}$ & & $\begin{array}{c}0.909 * * * \\
(0.160)\end{array}$ & $\begin{array}{c}0.762 * * * \\
(0.160)\end{array}$ & $\begin{array}{c}0.840 * * * \\
(0.161)\end{array}$ & $\begin{array}{c}0.840 * * * \\
(0.161)\end{array}$ \\
\hline Last game, $\$ 5$ stake & & $\begin{array}{c}0.774 \\
(0.558)\end{array}$ & & $\begin{array}{c}0.336 \\
(0.547)\end{array}$ & $\begin{array}{c}0.199 \\
(0.466)\end{array}$ & $\begin{array}{c}1.039 * * \\
(0.523)\end{array}$ \\
\hline Last game, $\$ 20$ stake & & $\begin{array}{c}0.081 \\
(0.320) \\
\end{array}$ & & $\begin{array}{l}-0.357 \\
(0.387) \\
\end{array}$ & $\begin{array}{l}-0.494 \\
(0.384) \\
\end{array}$ & $\begin{array}{c}0.346 \\
(0.274) \\
\end{array}$ \\
\hline Last game, $\$ 50$ stake & & $\begin{array}{c}1.468^{* * *} \\
(0.564)\end{array}$ & & $\begin{array}{l}1.030 * \\
(0.536)\end{array}$ & $\begin{array}{c}1.467^{* * *} \\
(0.465)\end{array}$ & $\begin{array}{c}2.307^{* * *} \\
(0.500)\end{array}$ \\
\hline Constant & $\begin{array}{c}-1.099 * * * \\
(0.144)\end{array}$ & $\begin{array}{c}-0.774 \text { *** } \\
(0.154)\end{array}$ & $\begin{array}{c}-0.814^{* * * *} \\
(0.075)\end{array}$ & $\begin{array}{c}-1.099 * * * \\
(0.144)\end{array}$ & $\begin{array}{c}-0.797^{* * * *} \\
(0.089)\end{array}$ & $\begin{array}{c}-0.797 * * * \\
(0.089)\end{array}$ \\
\hline Observations & 624 & 624 & 624 & 624 & 624 & 624 \\
\hline Log Likelihood & -384.089 & -390.397 & -360.528 & -381.598 & -357.020 & -357.020 \\
\hline Akaike Inf. Crit. & 772.177 & 788.794 & 745.057 & 773.195 & 744.041 & 744.041 \\
\hline$\$ 5$ vs. $\$ 20$ Stake Wald test $p$-value & & 0.39 & & 0.39 & 0.42 & 0.41 \\
\hline$\$ 20$ vs. $\$ 50$ Stake Wald test $p$-value & & 0.08 & & 0.08 & 0.03 & 0.03 \\
\hline Session FE & No & No & Yes & No & Yes & Yes \\
\hline
\end{tabular}

Note: ${ }^{*} p<0.1 ;{ }^{* *} p<0.05 ;{ }^{* * *} p<0.01$. Standard errors in parentheses are clustered at the session level (11 session clusters). Base category for stakes are the games before the last game of the sessions. The units of observation are group games (see Table 1). Specification (6) excludes last games from late game dummy. 
Table 3. Percentage of proposed coalitions at the start of every game, by agent power.

\begin{tabular}{ccccc}
\hline & $\{\mathbf{2 0 , 3 5 , 4 5}\}$ & $\{\mathbf{2 0 , 3 5}\}$ & $\{\mathbf{2 0 , 4 5}\}$ & $\{\mathbf{3 5 , 4 5}\}$ \\
\hline Power $=20$ & 60 & 34 & 6 & - \\
Power $=35$ & 20 & 73 & - & 7 \\
Power $=45$ & 33 & - & 40 & 27 \\
\hline \multicolumn{5}{c}{ Note: Rows sum to $100 \%$} \\
\hline \multicolumn{7}{c}{. }
\end{tabular}

Panels (A) and (B) of Table 4 show that proposing to the lower-powered Agent 20 may be consistent with the possibility of the strategies being an empirical best response, given that Agent 20 has a positive probability of behaving myopically (that is, accepting a two-person coalition when he has the lower power). ${ }^{20}$ In Panel (A), Agent 35 maximizes his expected pay-off by proposing the coalition $\{20,35\}$ where he gets an expected pay-off of $\$ 2.84$. Similarly, in Panel (B) Agent 45 obtains his maximum expected pay-off by proposing $\{20,45\}$. In early games, proposing a two-person coalition to the agent with the least power and becoming a dictator is even more lucrative. For instance, a 35-powered agent will get $\$ 3.11$ in expected payoffs by proposing $\{20,35\} .^{21}$ As agents learn more about how to play the experiment in late games, the expected pay-off of proposing to the lowest-powered agent diminishes in late games (bottom part of Panels (A) and (B)). On the other hand, Agent 20 maximizes the expected pay-off by proposing the grand coalition in all games (see Appendix B Tables A1-A3).

Table 4. Expected payoffs by proposal strategy.

\begin{tabular}{|c|c|c|c|c|c|c|}
\hline & \multicolumn{3}{|c|}{ (A) } & \multicolumn{3}{|c|}{ (B) } \\
\hline & \multicolumn{3}{|c|}{ Agent with Power 35} & \multicolumn{3}{|c|}{ Agent with Power 45} \\
\hline Proposed Coalition & $\{20,35,45\}$ & $\{20,35\}$ & $\{35,45\}$ & $\{20,35,45\}$ & $\{20,45\}$ & $\{35,45\}$ \\
\hline Expected pay-off (\$) & 1.80 & 2.84 & 0 & 1.40 & 2.62 & 2.49 \\
\hline $\begin{array}{c}\text { Early games } \\
\text { Proposed Coalition } \\
\text { Expected pay-off }(\$)\end{array}$ & $\begin{array}{c}\{20,35,45\} \\
2.07\end{array}$ & $\begin{array}{c}\{20,35\} \\
3.11\end{array}$ & $\begin{array}{c}\{35,45\} \\
0\end{array}$ & $\begin{array}{c}\{20,35,45\} \\
1.05\end{array}$ & $\begin{array}{c}\{20,45\} \\
2.81\end{array}$ & $\begin{array}{c}\{35,45\} \\
2.54\end{array}$ \\
\hline $\begin{array}{l}\text { Late games } \\
\text { Proposed Coalition } \\
\text { Expected pay-off }(\$)\end{array}$ & $\begin{array}{c}\{20,35,45\} \\
1.63\end{array}$ & $\begin{array}{c}\{20,35\} \\
2.61\end{array}$ & $\begin{array}{c}\{35,45\} \\
0\end{array}$ & $\begin{array}{c}\{20,35,45\} \\
1.65\end{array}$ & $\begin{array}{c}\{20,45\} \\
2.28\end{array}$ & $\begin{array}{c}\{35,45\} \\
2.44\end{array}$ \\
\hline
\end{tabular}

Note: These are the proposals made in the first round of every game.

Figure 4 shows the evolution of these proposals throughout the games. We can see that for agents with power 20 , the proportion of the grand coalition being proposed gradually rises. This may be an indication that these low-powered agents learn and comprehend that proposing the grand coalition will likely include them in the final coalition. The trend of increasing the proportion of grand coalition proposals is also true for agents with 35 and 45, although statistical tests show that the increase is milder for Agent 35 (see the logit model in Table A4). This finding is consistent with the results in Table 4, where we note that for Agent 35, proposing the two-person coalition with the lower-powered agent remains an empirical best response that provides him with the highest expected pay-off among all his proposal strategies. On the other hand, for Agent 45 we can see that in late games the gap in

20 The complete details on how to obtain the expected payoffs in these tables are shown in Appendix B.

21 There may be other explanations as to why subjects propose or accept two-person coalitions, such as errors (or anticipation of errors) and reciprocity. If there is a small chance of the weaker player accepting a two-person coalition by mistake, then there it is in the best interest of the stronger player to propose such a coalition. On the other hand, a weaker player proposing a two-person coalition can be viewed as a trust game. The weaker player takes the risk in increasing the other player's share in the hope that the stronger player reciprocates by not eliminating him. These issues are beyond the scope of this paper, and so we leave these for further studies. 
expected pay-off from proposing the two-person coalition with Agent 20 and proposing the grand coalition becomes narrower. For Agent 45, the expected pay-off of proposing $\{20,45\}$ vs. $\{20,35,45\}$ is $\$ 2.81$ vs. $\$ 1.05$ in early games and $\$ 2.28$ vs. $\$ 1.65$ in late games. For Agent 20 , the expected pay-off from proposing the grand coalition increases from $\$ 0.59$ in early games to $\$ 0.66$ in late games (Appendix $B$ Tables A2 and A3).
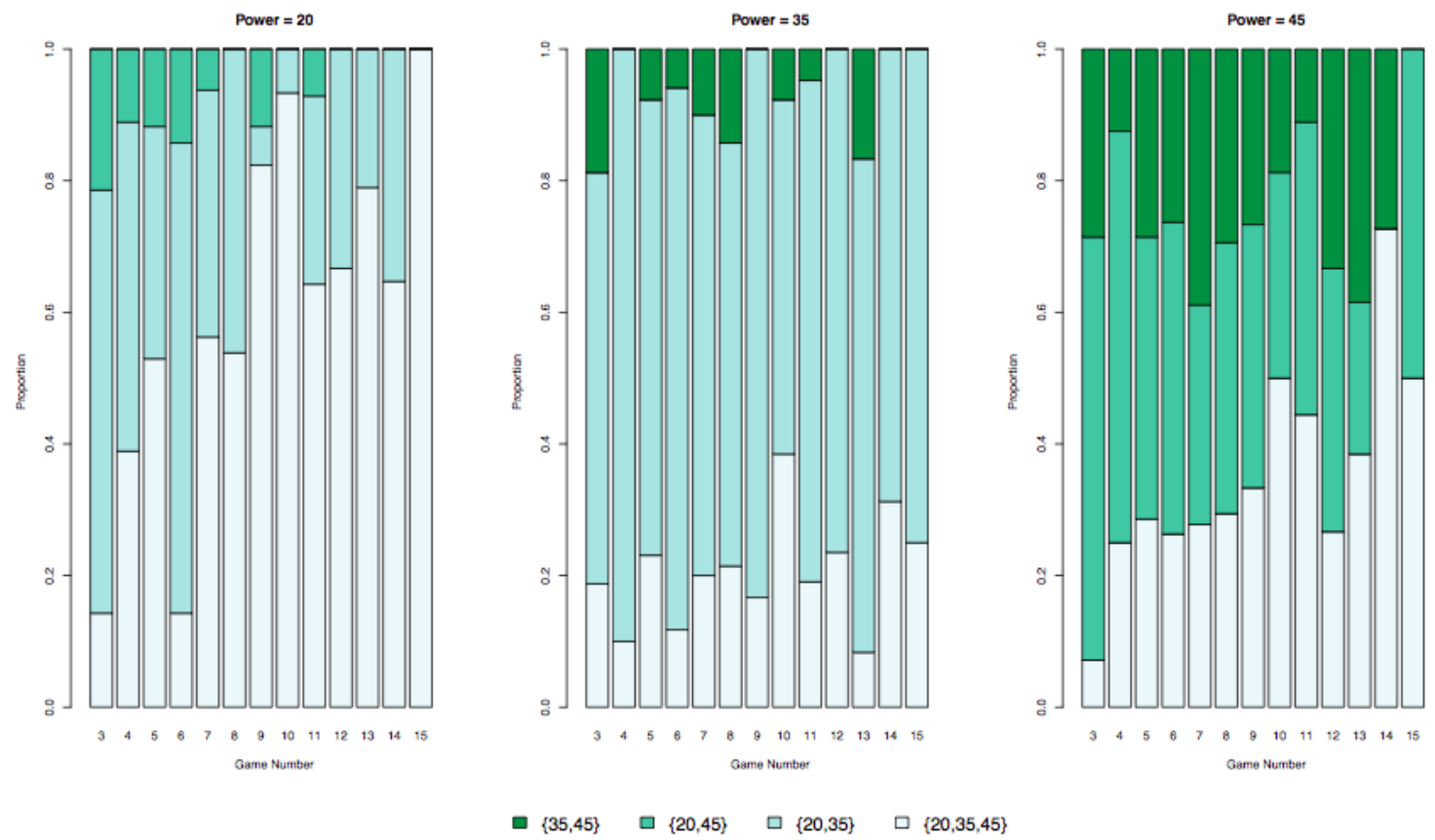

Figure 4. Percentage of proposed coalition at the start of every game, by game and agent's power.

Observation 4. Responses are dependent on an agent's drawn power. Higher-powered agents tend to accept two-person coalitions offered by an agent with a lower power. A substantial proportion of responses accept the grand coalition when offered.

Table 5 shows some interesting patterns regarding the agents' responses. First, higher-powered agents tend to accept overwhelmingly a two-person coalition with a lower-powered agent. For instance, Agent 35 almost always accepts $\{20,35\}$ and Agent 45 always accepts $\{20,45\}$ and $\{35,45\}$. This strategy may be consistent with both a subgame perfect equilibrium strategy (off the equilibrium path) and exhibiting other-regarding behavior (Bolton and Ockenfels [36]), in the sense that they care for the lower-powered agent, in order to acquire a higher share than staying with the grand coalition. However, the latter may not be true because, as Figure 2 shows, the proportion of two-person final coalition-forming seems to be relatively low. Hence, the two-person coalition will be more likely to deviate into a singleton rather than stay at the two-person coalition. In Table A1, for instance, if Agent 20 proposes $\{20,35\}$ and it passes, $79 \%$ of the time it will degenerate into a singleton coalition where 35 is the dictator.

Table 5. Percentage of responses at the start of every game, by agent's power and proposed coalition.

\begin{tabular}{ccccccccc}
\hline & \multicolumn{2}{c}{$\mathbf{2 0 , 3 5 , 4 5}$} & \multicolumn{2}{c}{$\mathbf{2 0 , 3 5}$} & \multicolumn{2}{c}{$\mathbf{2 0 , 4 5}$} & \multicolumn{2}{c}{$\mathbf{3 5 , 4 5 \}}$} \\
\cline { 2 - 9 } & Accept & Reject & Accept & Reject & Accept & Reject & Accept & Reject \\
\hline Power $=20$ & 31 & 1 & 17 & 26 & 10 & 15 & - & - \\
Power $=35$ & 51 & 10 & 20 & 2 & - & - & 6 & 11 \\
Power $=45$ & 81 & 5 & - & - & 7 & 0 & 7 & 0 \\
\hline
\end{tabular}

Note: Rows sum to $100 \%$. 
Another interesting pattern is that the agent who draws power 45 faces a proposed grand coalition $86 \%$ of the time, but the agent with power 35 only faces a proposed grand coalition around $61 \%$ of every first round of proposals (Table 5). This finding is indicative of a reluctance by the lower-powered agents to include 45 in a two-person coalition, since they know that it could lead to two things: First, they could get a relatively lower pay-off compared to a two-person coalition with a lower-powered agent, and second, they know that Agent 45 can kill them. This behavior may be consistent with both empirical expected pay-off maximization and farsighted behavior. ${ }^{22}$

Figure 5 shows how these responses evolve throughout the games. ${ }^{23}$ For an agent with drawn power 20, the proportion of rejecting two-person coalitions increases throughout the games and at the same time the proportion of accepting the grand coalition also increases (see the logit model in Table A6 in Appendix C). For both agents drawing powers 35 and 45, the proportion of accepted grand coalitions increases over time. Agent 45 almost always faces a proposed grand coalition, most of which are accepted (see the logit model in Table A5 in Appendix C).
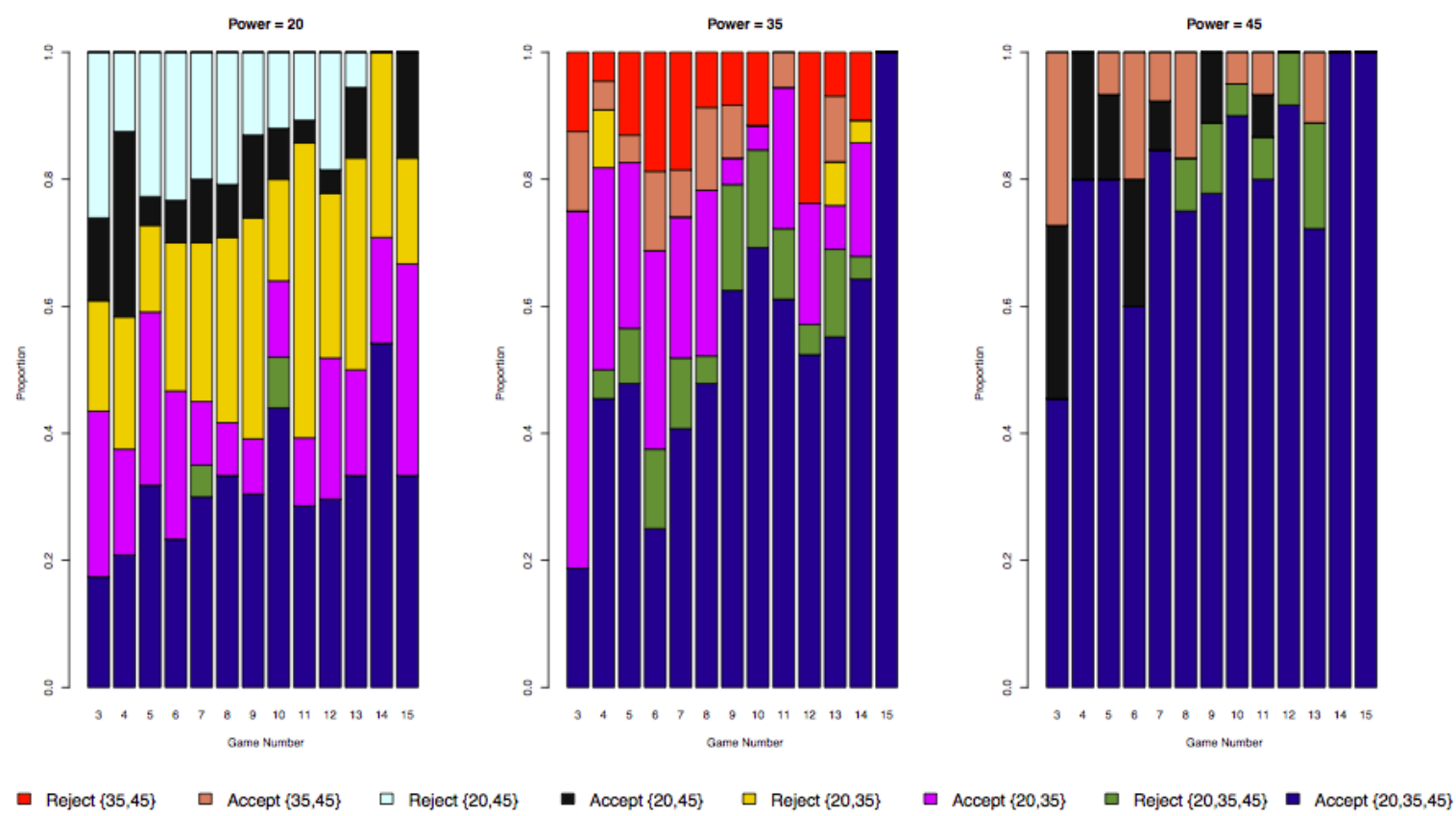

Figure 5. Percentage of responses at the start of every game, by game and agent's power.

\subsection{Typology of Agents}

In the previous subsection we looked at the type of strategies that were played in the experiment. Here we will attempt to categorize subjects into several types depending on the choices they made in our game. Please note that the subjects may play different types of strategies throughout the games, and in this exercise we will attempt to assign subjects based on a scoring method called quadratic deviation measure $(\mathrm{QDM})^{24}$. This measure takes the quadratic difference between the actual choice vector of a subject in a potential move and the choice vector predicted by the model. Let $c_{i, \alpha(m)}(t)=\left[c_{i, \alpha(m)}(1), \ldots, c_{i, \alpha(m)}(T)\right]$ be the strategy choices that an agent makes in round $t$ given a model $m$, whether he is a proposer or a responder. Please note that the choice can be any coalition

22 This is also consistent with the results in Table 3 where the grand coalition constitutes $60 \%$ of Agent 20's proposals while coalition $\{20,45\}$ only constitutes $6 \%$ of his proposals. Agent 35 , on the other hand, proposes the grand coalition $20 \%$ of the time while proposing $\{35,45\}$ only $7 \%$ of the time.

23 In Appendix C, we further analyze the proposal and response strategies using a logit model that further corroborates the main findings of this section.

24 See Nagel and Fang [37] as well as Selten [38] for an axiomatic analysis of the method. 
if he is a proposer, or whether to accept or reject the coalition if he is a responder. Specifically, each element in this choice vector takes on the value

$$
c_{i, \alpha(m)}(t)= \begin{cases}1 & \text { if strategy } \alpha \text { prescribed by model } m \text { is chosen in round } t \\ 0 & \text { otherwise }\end{cases}
$$

Here, we choose three types of models. First, the equilibrium model where agents play the subgame perfect equilibrium strategies. In our setting, this corresponds to subjects proposing $\{20,35,45\}$ and nothing else, and accepting $\{20,35,45\}$. Also part of the SPNE strategy is to accept a two-person coalition whenever an agent has the higher power. Hence, the choice vector $c_{i, \alpha(e q)}(t)$ will get 1 in the $t$ th index if he is a proposer and he proposes $\{20,35,45\}$ or if he is a responder and he accepts $\{20,35,45\}$ or accepts a two-person coalition if he has the higher power. Otherwise, the vector registers a zero in the $t$ th index. The second type of model is the myopic model. In this model, agents play myopic strategies where lower-powered agents propose a two-person coalition with a higher-powered agent when it is his turn to propose, or accept a two-person coalition with a higher-powered agent when it is time to respond. Here, the choice vector $c_{i, \alpha(m y o)}(t)$ will get 1 in the $t$ th index if, for instance, a subject has power 20 and he proposes $\{20,35\}$ or $\{20,45\}$. If Agent 20 is a responder and he accepts $\{20,35\}$ or $\{20,45\}$ then he also gets a 1 on the $t$ th index. The third type of model is where subjects play their empirical best response. Here, if an agent is a proposer, he will propose to a lower-powered agent or propose himself if a two-person coalition has formed. If he is a responder, he will accept a two-person coalition from a lower-powered agent or reject a two-person coalition if he has a lower power. Here, the choice vector $c_{i, \alpha}(e b r)(t)$ will get 1 in the th index if, for instance, a subject has power 45 and he proposes $\{20,45\}$ or $\{35,45\}$. If Agent 45 is a responder and he accepts $\{20,45\}$ or $\{35,45\}$ then he also gets a 1 on the $t$ th index. ${ }^{25}$ We have shown that this strategy is consistent with maximizing the expected payoffs given the empirical probabilities given in Tables A1-A3.

Let $p_{i, \alpha(m)}(t)=\left[p_{i, \alpha(m)}(1), \ldots, p_{i, \alpha(m)}(T)\right]$ be the vector of predicted choices given a model. This vector will register a 1 on the $t$ th index if there is an opportunity to play a strategy prescribed by a model. For instance, in the empirical best response model if you have power 35 or 45 and are chosen to be a proposer in round 1, then you have the opportunity to play a best response strategy (i.e., propose to a lower-powered agent) and thus a 1 is registered in the first index if you are a proposer. Hence,

$$
p_{i, \alpha(m)}(t)= \begin{cases}1 & \text { if strategy } \alpha \text { can be played in round } t \\ 0 & \text { otherwise }\end{cases}
$$

The quadratic deviation measure for a particular agent $i$ in model $m$ is thus given by:

$$
Q D M_{i, m}=\frac{\sum_{t}^{T}\left(c_{i, \alpha(m)}(t)-p_{i, \alpha(m)}(t)\right)^{2}}{T}
$$

Clearly, a $Q D M_{i, m}$ closer to zero indicates a high proportion of strategies employed by the agents coinciding with those prescribed by model $m$. We then categorize the subjects into equilibrium agents, myopic agents, or empirical best response agents by simply taking the minimum of QDMs for the three models for each subject $i$, i.e.,

$$
\text { type }_{i}=\left\{\begin{array}{l}
\text { Equilibrium if } Q D M_{i, e q}=\operatorname{argmin}\left(Q D M_{i, e q}, Q D M_{i, m y o}, Q D M_{i, e b r}\right) \\
\text { Myopic if } Q D M_{i, m y o}=\operatorname{argmin}\left(Q D M_{i, e q}, Q D M_{i, m y o}, Q D M_{i, e b r}\right) \\
\text { Empirical Best Response if } Q D M_{i, e b r}=\operatorname{argmin}\left(Q D M_{i, e q}, Q D M_{i, m y o}, Q D M_{i, e b r}\right)
\end{array}\right.
$$

25 Here we note that Agent 20's empirical best response coincides with his subgame perfect equilibrium strategies. 
Table 6 summarizes the subject types across sessions for all games, early games, and late games. It is clear that there are very diverse types of agents in the experiment. About $44 \%$ of the agents can be classified as "equilibrium agents", $23 \%$ can be classified as "myopic", while $33 \%$ can be classified as playing "equilibrium best response" strategies. There is also substantial heterogeneity within sessions, as some are dominated by equilibrium agents, such as the 4 February 2015, AM session, and some are dominated by myopic agents, such as the 23 June 2014, session.

An interesting pattern is the decrease in the number of myopic agents, as well as the increase in the number of equilibrium agents, when we move to late games. For instance, in early games $29 \%$ of the agents are classified as myopic, but this percentage declines to $19 \%$ in late games. The proportion of equilibrium agents increases from $41 \%$ in early games to $55 \%$ in late games. This echoes the recurring finding that agents seem to learn as they play our coalition formation game. This increase in the number of equilibrium agents, and the decrease in myopic agents, is probably the reason the proportion of grand coalitions increases in the late rounds. 
Table 6. Subject type by session for all games, early games, and late games.

\begin{tabular}{|c|c|c|c|c|c|c|c|c|c|c|}
\hline \multirow[b]{2}{*}{ Sessions } & \multirow[b]{2}{*}{ Number of Subjects } & \multicolumn{3}{|c|}{ All Games } & \multicolumn{3}{|c|}{ Early Games } & \multicolumn{3}{|c|}{ Late Games } \\
\hline & & Equilibrium & Myopic & $\begin{array}{c}\text { Empirical } \\
\text { Best Response }\end{array}$ & Equilibrium & Myopic & $\begin{array}{c}\text { Empirical } \\
\text { Best Response }\end{array}$ & Equilibrium & Myopic & $\begin{array}{c}\text { Empirical } \\
\text { Best Response }\end{array}$ \\
\hline 6 May 2014, AM & 12 & 5 & 2 & 5 & 6 & 2 & 4 & 7 & 2 & 3 \\
\hline 6 May 2014, PM & 15 & 9 & 2 & 4 & 8 & 2 & 5 & 7 & 4 & 4 \\
\hline 7 May 2014 & 12 & 7 & 3 & 2 & 5 & 4 & 3 & 8 & 2 & 2 \\
\hline 5 June 2014 & 9 & 1 & 4 & 4 & 3 & 4 & 2 & 4 & 3 & 2 \\
\hline 6 June 2014 & 12 & 3 & 4 & 5 & 1 & 4 & 5 & 5 & 2 & 5 \\
\hline 23 June 2014 & 9 & 0 & 7 & 2 & 3 & 5 & 1 & 0 & 6 & 3 \\
\hline 24 June 2014 & 6 & 2 & 1 & 3 & 1 & 2 & 3 & 4 & 1 & 1 \\
\hline 4 February 2015, AM & 15 & 10 & 1 & 4 & 8 & 5 & 2 & 11 & 1 & 3 \\
\hline 4 February $2015, \mathrm{PM}$ & 15 & 9 & 1 & 5 & 8 & 4 & 3 & 11 & 1 & 3 \\
\hline 5 February 2015, AM & 12 & 5 & 4 & 3 & 4 & 4 & 4 & 6 & 2 & 4 \\
\hline 5 February2015, PM & 15 & 7 & 2 & 6 & 8 & 2 & 5 & 10 & 1 & 4 \\
\hline Overall (Number) & 132 & 58 & 31 & 43 & 55 & 38 & 39 & 73 & 25 & 34 \\
\hline Overall (Percentage) & 100 & 44 & 23 & 33 & 41 & 29 & 30 & 55 & 19 & 26 \\
\hline Min QDM & & 0 & 0.12 & 0 & 0 & 0 & 0 & 0 & 0 & 0 \\
\hline Max QDM & & 7.31 & 11.6 & 7.68 & 3.26 & 10.56 & 3.27 & 4.76 & 10.56 & 5.33 \\
\hline Mean QDM & & 1.39 & 3.17 & 1.40 & 0.83 & 1.51 & 0.65 & 0.74 & 1.88 & 0.89 \\
\hline
\end{tabular}




\section{Conclusions}

The experiment conducted in this paper highlights how nuances in assumptions regarding human behavior affect how coalitions form and evolve. Dictatorships will be more common if agents behave myopically - that is, if they do not take into account further possible ramifications of joining a particular group. If agents are farsighted, the greater the chance that groups will not degenerate into a dictatorship. Our results in this paper suggest that agents' behavior is more complicated than the assumptions set out in AES. Indeed, we actually observe a lot of rational behavior, with some agents taking advantage of myopic agents, especially in early games when they do not have much experience of playing. This behavior naturally leads to a proliferation of dictatorships. However, given sufficient time, the agents learn how to behave more strategically and rationally, therefore avoiding being part of a coalition where they could be sidelined in the future.

This paper has yielded important insights. First, the strategies are contingent on the agents' drawn power. In particular, many agents play their empirical best response to the possibility that their counterparts will behave myopically. For instance, higher-powered agents propose the coalition with Agent 20 in it, which is consistent with the behavior where agents maximize their expected pay-off by taking advantage of the probability that Agent 20 will play myopically and accept the coalition, which could then lead the higher-powered agent to form a dictatorship. Second, there is some hysteresis in how agents play their strategies. For instance, agents who tend to accept a two-person coalition or reject the grand coalition the last time they were a responder increase the probability that they would accept a two-person coalition when tasked with responding to such a coalition. This is an indication of the consistency of behavioral types. In addition, there is evidence of more cooperative behavior with higher stakes.

Given our experimental setup, it is hard to disentangle strategies that exhibit some of the common behavioral phenomena such as other-regarding behavior. After all, proposing the grand coalition in this experiment is also consistent with having pro-social preferences. However, in most cases, there is evidence to suggest that this behavior can be ruled out. For instance, when faced with a two-person coalition with a lower-powered agent, an overwhelming proportion of these agents will propose themselves as the dictator. ${ }^{26}$ Apart from pro-social preferences, other pertinent issues that need to be disentangled is the role of errors and reciprocity in the agents' coalition formation strategies.

All these results taken together suggest that elements overlooked by AES are important in understanding the richness and complexity of how people form groups. From this experiment, we see that people are rational, albeit through a trial-and-error learning process. The presence of a small number of myopic players is enough to drive rational agents to propose a two-person coalition, which points to the importance of the heterogeneity of behavioral types in the coalition formation process.

There are several ways to extend our coalition formation experiment. First, the experiment can investigate how the sharing rules affect how coalitions are formed. In our particular coalition formation game, the theoretical prediction will not change if we change our sharing rule to equal sharing. ${ }^{27}$ It is an open question whether the proportion of grand coalition-forming will be different under the two sharing rules.

There is also the issue of endogenizing the sharing rule. Apart from the coalition that can form, agents can bargain over the split of the prize as well. This issue is still a loose end for both theory and experiments.

26 The only case where it does not happen is in the late games, when Agent 45 proposes $\{20,45\}$ and, if passed, about $60 \%$ of the time this two-person coalition still forms.

27 Equal sharing or proportional sharing satisfy a property whereby agents have the same ordinal ranking over coalitions in which they belong. See Jandoc and Juarez [39] for a more detailed discussion of this property they call "consistent ranking". 
In the case of proportional sharing, it may be rational for a high-powered agent to "decrease" his power to incentivize other agents to include him in a self-enforcing coalition. Whether high-powered agents actually accumulate or decrease power when given the option is an interesting study for both theory and experiment.

Author Contributions: Conceptualization, K.J. and R.J.; methodology, K.J. and R.J.; validation, K.J. and R.J.; formal analysis, K.J and R.J.; writing—original draft preparation, K.J. and R.J.; writing—review and editing, K.J. and R.J.

Funding: This research was funded by the AFOSR Young Investigator Program, the Philippine Center for Economic Development, and UPEcon-HPDP.

Acknowledgments: We thank the Editor and two anonymous referees for helpful remarks and suggestions. We also thank Katya Sherstyuk for detailed comments and advice throughout this project. We thank Ryan Morisato and Bryson Yee for helping us run the experiments. We appreciate comments from Daron Acemoglu, Georgy Egorov, Konstantin Sonin, Guillaume Frechette, David Porter, and Marc Willinger, and multiple comments by participants at conferences and seminars, including the 2014 Economic Science Association International Conference in Honolulu, 2016 Meeting of the Society for Social Choice and Welfare in Lund, and the 2017 Conference on Economic Design in York. Any errors or omissions are the authors' own.

Conflicts of Interest: The authors declare no conflict of interest.

\section{Appendix A. Experiment Instruction and Quiz}

\section{Appendix A.1. Oral Instructions Given to Students}

The instructions were given carefully, following the script below. Steps 1-6 were given only at the beginning, Step 7 after every game, and Step 8 before starting the last game.

1. Good afternoon, everyone, in a few minutes we will be starting our experiment. Please sign the consent form that basically tells us that you agree to participate in this experiment. If at any time you feel uncomfortable with the experiment, please inform us and you will have the option to leave it.

2. A few house rules: Always remember that you cannot talk with anyone while doing the experiment. Please refrain from texting, browsing, or any other activity not related to the experiment. If you have any questions, please raise your hand and ask the experimenters and they will address your concerns.

3. We will be watching a video that gives instructions to the experiment. Be sure you use your headphones so that you do not bother anyone. Again, if there are any questions regarding the video instructions, please raise your hand. (The video was played for every student in a computer and headset available in the lab. Students had the option to rewind, pause/play the video at any time. See link to video and screenshots below).

4. Please go to Google Chrome and open the following link (given to students after everyone finished watching the video). The link contains a quiz to test whether you have understood the instructions in the video. Again, if there are any questions, please raise your hand (see quiz below).

5. We are handing out the earnings sheet. We have two (2) practice games that are designed to familiarize you with the game. You will not be paid in these practice games. After the practice games, we will play up to twelve (12) games, where you will be paid based on your performance. The pot for each game is $\$ 5$. You must write your SEC number, your power, and your final pay-off for each game. Your final pay-off that will appear in your screen is in dollar amounts.

6. Now, we will be handing out strips of paper that contain a website's details. Please copy the address as it appears on the strip of paper. Remember that the address is case-sensitive.

Step 7 was repeated for up to 13 times, for every game after the initial and final game.

7. Please close all windows now. We will be handing out new strips of paper with the website that you should go to. 
The next step notifies the student that this is the final game. It also tells them the pot amount of the final game (keep at $\$ 5$ or increase to \$20-\$50). Please note that students were never notified about the availability of the $\$ 20 / \$ 50$ pots until the start of the final game.

8. The next is the final game. We will increase the pot from $\$ 5$ to $\$ 20 / \$ 50$ (keep the pot at $\$ 5$ dollars). Appendix A.2. Screenshots of Video and Instructions

Instructions for the experiment can be viewed in the following link: https: / / www.youtube.com/ watch?v=ECl6kXPYyh8.

The following are screenshots of the instructions. The video begins with the introduction frame:

\section{Instructions}

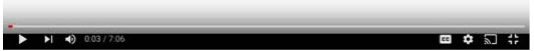

Figure A1. Screenshot of the instructions video.

The instructions then proceed to describe the proposal stage and response stage.

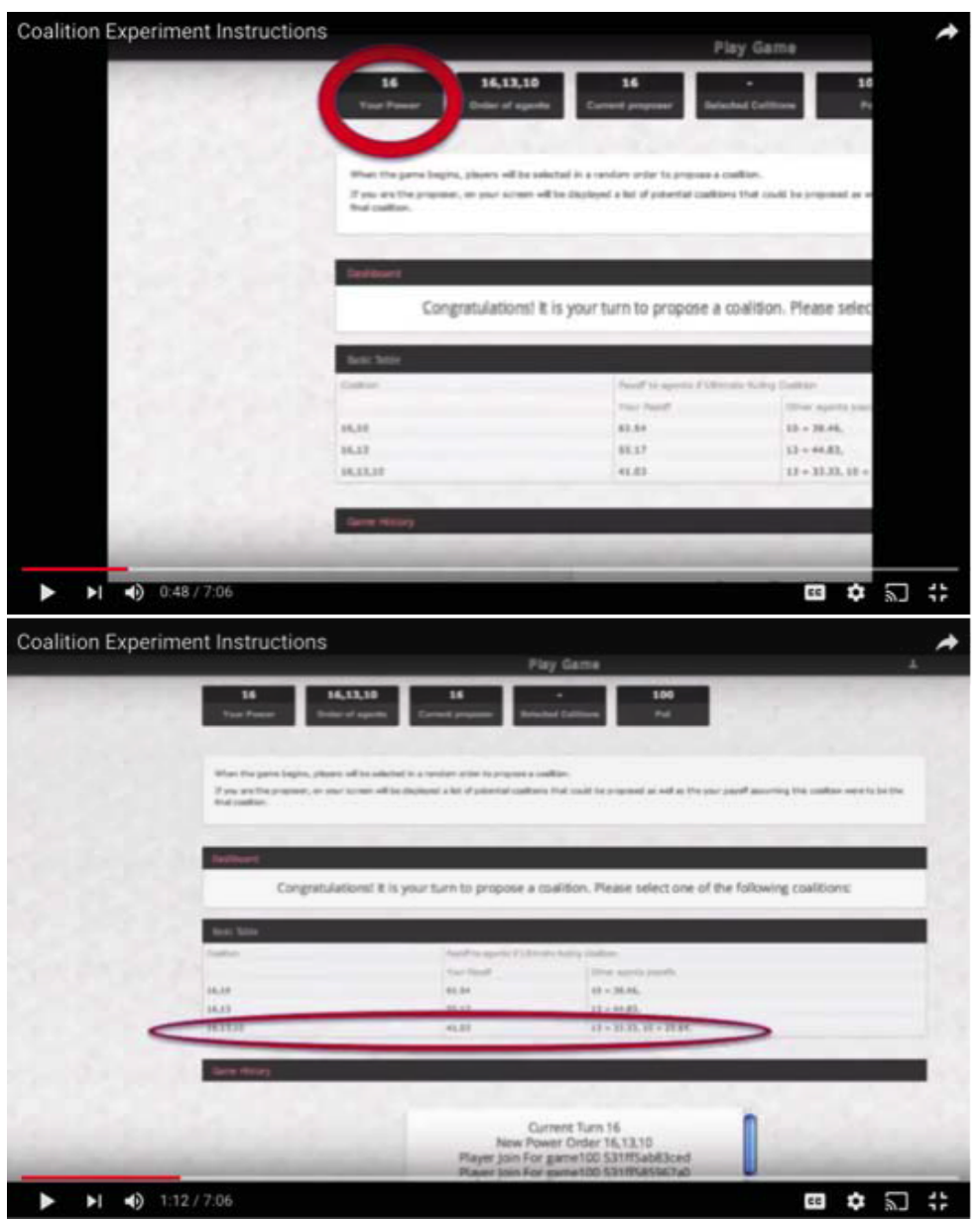

Figure A2. Screenshot of the instructions video:proposal stage. 


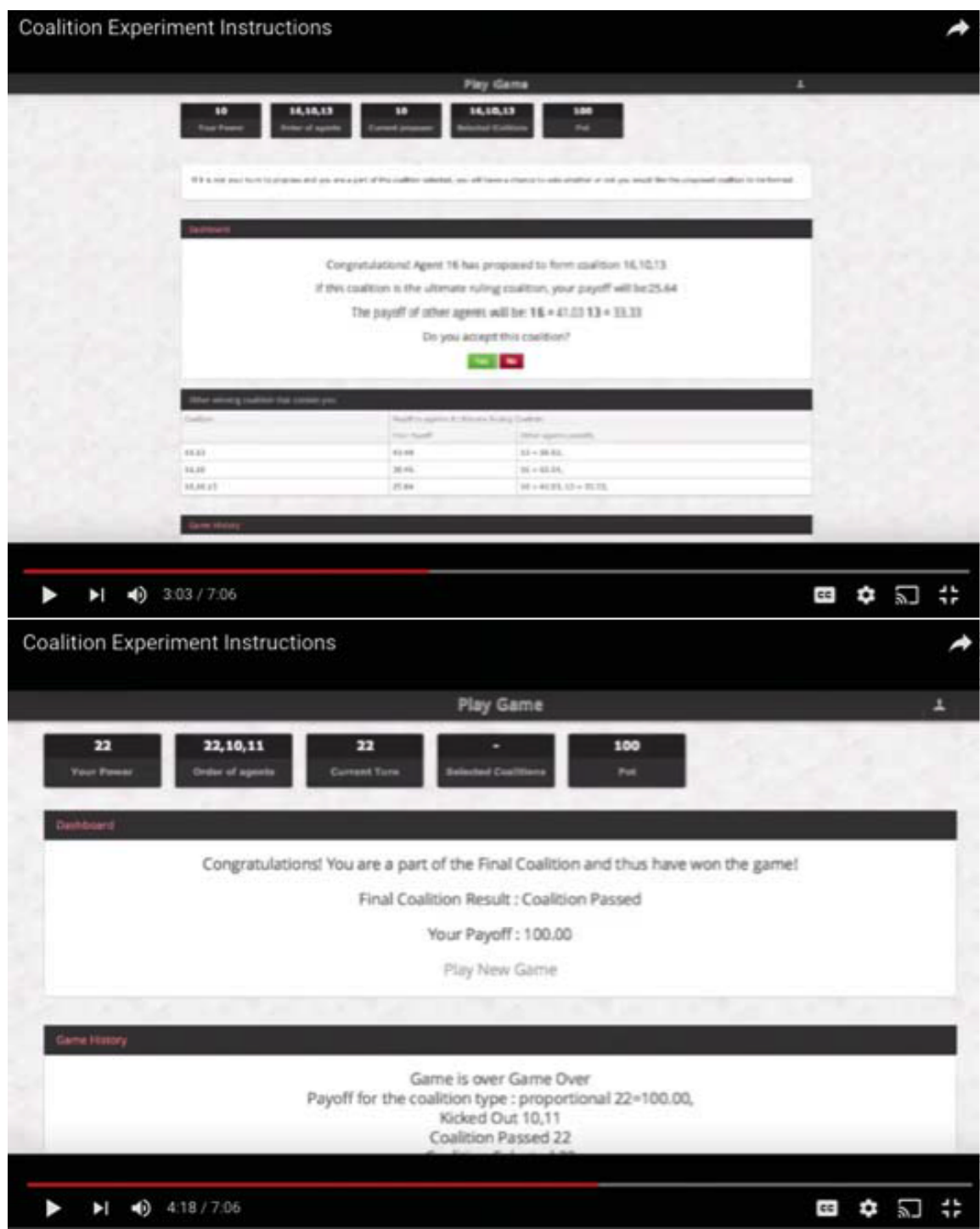

Figure A3. Screenshot of the instructions video:response stage.

After showing the instructions for the game, subjects were given an online quiz to test their knowledge of the general instructions and the game. Each question in the quiz showed them a screenshot of the game. There were five questions in the quiz, corresponding to the different parameters of the game (e.g., subjects own power), the payoffs, the order of proposals, and the different stages of the game. The subject was not able to proceed to take part in the experiment if he had not finished the quiz. The following are the questions asked:

Question 1: What is your power?

Question 2: What is your pay-off if the proposed coalition is accepted?

Question 3: What are the powers of your opponents?

Question 4: If the coalition proposed by player with power 13 were to be rejected, what is the power of the player who would propose a coalition next?

Question 5: If the player with powers 20 and 25 voted in favor of a coalition, and players with powers 5,10 , and 15 voted against, would the coalition be accepted or rejected? 


\section{Appendix B. Proposal Strategies and Expected Payoffs}

Table A1 shows the proposals strategies in detail. Line (1) shows the possible coalitions that can be proposed. For instance, for the agent who has drawn power 20, the possible coalitions he can propose are $\{20,35,45\},\{20,35\}$, or $\{20,45\}$. Line (2) shows the percentage of the proposed coalition in relation to the total number of proposals made by the agent drawing a particular power. Hence, coalitions $\{20,35,45\}$ comprise $60 \%$ of the total proposals made by agent 20 . Line (3) indicates whether the proposed coalition passed (i.e., a majority of agents voted "yes" for this proposed coalition) or failed (i.e., the proposer failed to muster enough "yes" votes), and line (4) shows the percentage of "passes" or "fails" for such proposals. ${ }^{28}$ After determining whether a proposed coalition has passed or failed, Line (5) lists the possible final coalitions that may form. For instance, if coalition $\{20,35\}$ passes for Agent 20, the possible final coalitions can either be $\{20,35\}$ (B) or the singleton $\{35\}$ (E). On the other hand, if $\{20,35\}$ fails, then the possible final coalitions will be the whole gamut of coalitions that can form, i.e., $\{20,35,45\},\{20,35\},\{20,45\},\{35,45\},\{35\}$, or $\{45\}$ (see the footnote of the table for the coalition A-F labels). Conditional on the coalition passing or failing, Line (6) then shows the percentage of each of the possible final coalitions. For example, if $\{20,35\}$ passes for agent $20,79 \%$ of the time it degenerates into the dictator coalition $\{35\}$. Line (7) shows the final pay-off if the specified coalition forms. Therefore, for Agent 20, coalition $B=\{20,35\}$ gives the agent $\frac{20}{20+35} \times 5=\{1.82\}$. Finally, Line (8) shows the expected payoffs of each of the proposal strategies by weighting each final pay-off with the appropriate proportions. Tables A2 and A3 present the same information for early and late games, respectively. 
Table A1. Expected payoffs by proposal strategy for each power draw, all games.

\begin{tabular}{|c|c|c|c|c|c|c|c|c|c|c|c|c|c|c|c|c|c|c|c|c|c|c|}
\hline \multirow{2}{*}{$\begin{array}{l}\text { Proposer }=20 \\
\text { (1) Proposed Coalition } \\
\text { (2) Percentage of Total Proposals } \\
\text { (3) Outcome of Response } \\
\text { (4) Outcome by Percentage } \\
\text { (5) Final Coalition (see Note) } \\
\text { (6) Frequency (Percentage) } \\
\text { (7) Final pay-off (\$) }\end{array}$} & \multicolumn{6}{|c|}{$\begin{array}{c}\{20,35,45\} \\
60 \\
\text { Pass } \\
100\end{array}$} & \multicolumn{8}{|c|}{$\begin{array}{c}\{20,35\} \\
34\end{array}$} & \multicolumn{8}{|c|}{$\begin{array}{c}\{20,45\} \\
6\end{array}$} \\
\hline & $\begin{array}{c}\text { A } \\
57 \\
1\end{array}$ & $\begin{array}{c}\mathrm{B} \\
4 \\
1.82\end{array}$ & $\begin{array}{c}\mathrm{C} \\
0 \\
1.54\end{array}$ & $\begin{array}{l}\mathrm{D} \\
1 \\
0\end{array}$ & $\begin{array}{c}\mathrm{E} \\
25 \\
0\end{array}$ & $\begin{array}{c}\mathrm{F} \\
13 \\
0\end{array}$ & $\begin{array}{c}\mathrm{B} \\
21 \\
1.82\end{array}$ & $\begin{array}{c}\mathrm{E} \\
79 \\
0\end{array}$ & $\begin{array}{c}\text { A } \\
40 \\
1\end{array}$ & $\begin{array}{c}\mathrm{B} \\
20 \\
1.82\end{array}$ & $\begin{array}{c}C \\
0 \\
1.54\end{array}$ & $\begin{array}{l}\mathrm{D} \\
20 \\
0\end{array}$ & $\begin{array}{l}\text { E } \\
0 \\
0\end{array}$ & $\begin{array}{l}\mathrm{F} \\
20 \\
0\end{array}$ & $\begin{array}{c}\mathrm{C} \\
8 \\
1.54\end{array}$ & $\begin{array}{l}\mathrm{F} \\
92 \\
0\end{array}$ & $\begin{array}{l}\text { A } \\
0 \\
1\end{array}$ & $\begin{array}{l}\mathrm{B} \\
0 \\
1.82\end{array}$ & $\begin{array}{l}\mathrm{C} \\
0 \\
1.54\end{array}$ & $\begin{array}{l}\mathrm{D} \\
0 \\
0\end{array}$ & $\begin{array}{l}\mathrm{E} \\
0 \\
0\end{array}$ & $\begin{array}{l}\text { F } \\
0 \\
0\end{array}$ \\
\hline (8) Expected pay-off (\$) & \multicolumn{6}{|c|}{0.64} & \multicolumn{8}{|c|}{0.42} & \multicolumn{8}{|c|}{0.12} \\
\hline $\begin{array}{l}\text { Proposer }=35 \\
\text { (1) Proposed Coalition } \\
\text { (2) Percentage of Total Proposals } \\
\text { (3) Outcome of Response } \\
\text { (4) Outcome by Percentage }\end{array}$ & \multicolumn{6}{|c|}{$\begin{array}{c}\{20,35,45\} \\
20 \\
\text { Pass } \\
100\end{array}$} & \multicolumn{8}{|c|}{$\begin{array}{c}\{20,35\} \\
73\end{array}$} & \multicolumn{8}{|c|}{$\begin{array}{c}\{35,45\} \\
7\end{array}$} \\
\hline $\begin{array}{l}\text { (5) Final Coalition (see Note) } \\
\text { (6) Frequency (Percentage) } \\
\text { (7) Final pay-off (\$) }\end{array}$ & $\begin{array}{c}\mathrm{A} \\
55 \\
1.75\end{array}$ & $\begin{array}{c}\mathrm{B} \\
0 \\
3.18\end{array}$ & $\begin{array}{l}\mathrm{C} \\
3 \\
0\end{array}$ & $\begin{array}{c}\mathrm{D} \\
0 \\
2.19\end{array}$ & $\begin{array}{c}\mathrm{E} \\
17 \\
5\end{array}$ & $\begin{array}{l}\mathrm{F} \\
25 \\
0\end{array}$ & $\begin{array}{c}\mathrm{B} \\
30 \\
3.18\end{array}$ & $\begin{array}{c}E \\
70 \\
5\end{array}$ & $\begin{array}{c}\mathrm{A} \\
70 \\
1.75\end{array}$ & $\begin{array}{c}\text { B } \\
4 \\
3.18\end{array}$ & $\begin{array}{l}\text { C } \\
0 \\
0\end{array}$ & $\begin{array}{c}\mathrm{D} \\
3 \\
2.19\end{array}$ & $\begin{array}{l}\text { E } \\
8 \\
5\end{array}$ & $\begin{array}{c}\mathrm{F} \\
15 \\
0\end{array}$ & $\begin{array}{c}\mathrm{D} \\
0 \\
2.19\end{array}$ & $\begin{array}{c}\mathrm{F} \\
100 \\
0\end{array}$ & $\begin{array}{c}\mathrm{A} \\
0 \\
1.75\end{array}$ & $\begin{array}{c}\text { B } \\
0 \\
3.18\end{array}$ & $\begin{array}{l}\mathrm{C} \\
0 \\
0\end{array}$ & $\begin{array}{c}\mathrm{D} \\
0 \\
2.19\end{array}$ & $\begin{array}{l}\mathrm{E} \\
0 \\
5\end{array}$ & $\begin{array}{c}F \\
100 \\
0\end{array}$ \\
\hline (8) Expected pay-off (\$) & \multicolumn{6}{|c|}{1.80} & \multicolumn{8}{|c|}{2.84} & \multicolumn{8}{|c|}{0} \\
\hline $\begin{array}{l}\text { Proposer }=45 \\
\text { (1) Proposed Coalition } \\
\text { (2) Percentage of Total Proposals } \\
\text { (3) Outcome of Response } \\
\text { (4) Outcome by Percentage }\end{array}$ & \multicolumn{6}{|c|}{$\begin{array}{c}\{20,35,45\} \\
33 \\
\text { Pass } \\
100 \\
\end{array}$} & \multicolumn{8}{|c|}{$\begin{array}{c}\{20,45\} \\
40\end{array}$} & \multicolumn{8}{|c|}{$\begin{array}{c}\{35,45\} \\
27\end{array}$} \\
\hline $\begin{array}{l}\text { (5) Final Coalition (see Note) } \\
\text { (6) Frequency (Percentage) } \\
\text { (7) Final pay-off (\$) }\end{array}$ & $\begin{array}{c}\text { A } \\
47 \\
2.25\end{array}$ & $\begin{array}{l}\text { B } \\
0 \\
0\end{array}$ & $\begin{array}{c}\mathrm{C} \\
0 \\
3.46\end{array}$ & $\begin{array}{c}\mathrm{D} \\
0 \\
2.81\end{array}$ & $\begin{array}{l}E \\
46 \\
0\end{array}$ & $\begin{array}{l}\mathrm{F} \\
7 \\
5\end{array}$ & $\begin{array}{c}C \\
25 \\
3.46\end{array}$ & $\begin{array}{c}\mathrm{F} \\
75 \\
5\end{array}$ & $\begin{array}{c}\mathrm{A} \\
45 \\
2.25\end{array}$ & $\begin{array}{c}\text { B } \\
14 \\
0\end{array}$ & $\begin{array}{c}\mathrm{C} \\
0 \\
3.46\end{array}$ & $\begin{array}{c}\mathrm{D} \\
0 \\
2.81\end{array}$ & $\begin{array}{c}E \\
34 \\
0\end{array}$ & $\begin{array}{l}\mathrm{F} \\
7 \\
5\end{array}$ & $\begin{array}{c}\mathrm{D} \\
12 \\
2.81\end{array}$ & $\begin{array}{c}\mathrm{F} \\
88 \\
5\end{array}$ & $\begin{array}{c}\text { A } \\
0 \\
2.25\end{array}$ & $\begin{array}{l}\text { B } \\
0 \\
0\end{array}$ & $\begin{array}{c}\mathrm{C} \\
0 \\
3.46\end{array}$ & $\begin{array}{c}\mathrm{D} \\
0 \\
2.81\end{array}$ & $\begin{array}{l}\text { E } \\
0 \\
0\end{array}$ & $\begin{array}{l}\mathrm{F} \\
0 \\
5\end{array}$ \\
\hline (8) Expected pay-off (\$) & \multicolumn{6}{|c|}{1.40} & \multicolumn{8}{|c|}{2.62} & \multicolumn{8}{|c|}{2.49} \\
\hline
\end{tabular}

Note: Final Coalitions labels are $A=\{20,35,45\}, B=\{20,35\}, C=\{20,45\}, D=\{35,45\}, E=\{35\}$, and $F=\{45\}$. See the text for an explanation of each of the rows. Note: These are the proposals made in the first round of every game. 
Table A2. Expected payoffs by proposal strategy for each power draw, early games.

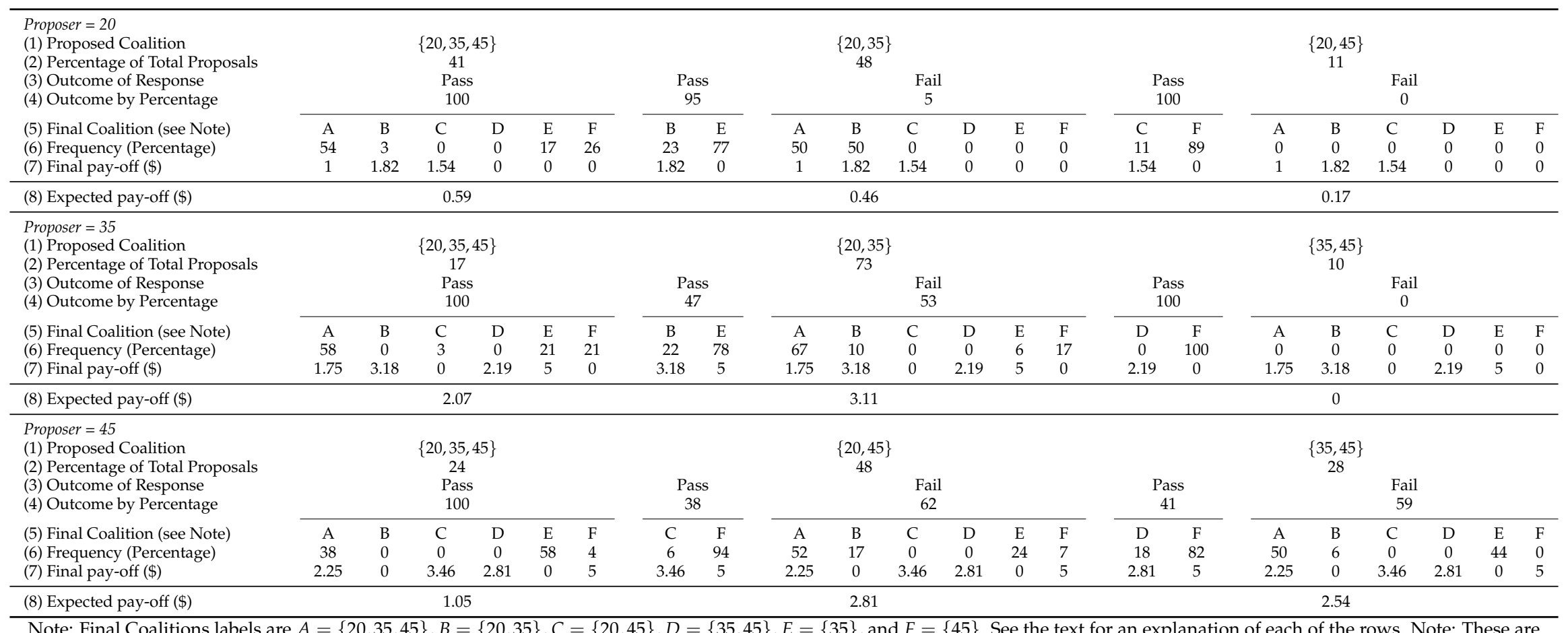

Note: Final Coalitions labels are $A=\{20,35,45\}, B=\{2$

the proposals made in the first round of every game. 
Table A3. Expected payoffs by proposal strategy for each power draw, late games.

\begin{tabular}{|c|c|c|c|c|c|c|c|c|c|c|c|c|c|c|c|c|c|c|c|c|c|c|}
\hline \multirow{2}{*}{$\begin{array}{l}\text { Proposer }=20 \\
\text { (1) Proposed Coalition } \\
\text { (2) Percentage of Total Proposals } \\
\text { (3) Outcome of Response } \\
\text { (4) Outcome by Percentage } \\
\text { (5) Final Coalition (see Note) } \\
\text { (6) Frequency (Percentage) } \\
\text { (7) Final pay-off (\$) }\end{array}$} & \multicolumn{6}{|c|}{$\begin{array}{c}\{20,35,45\} \\
76 \\
\text { Pass } \\
100\end{array}$} & \multicolumn{8}{|c|}{$\begin{array}{c}\{20,35\} \\
21\end{array}$} & \multicolumn{7}{|c|}{$\begin{array}{c}\{20,45\} \\
3\end{array}$} & \\
\hline & $\begin{array}{c}\text { A } \\
59 \\
1\end{array}$ & $\begin{array}{c}\mathrm{B} \\
4 \\
1.82\end{array}$ & $\begin{array}{c}\mathrm{C} \\
0 \\
1.54\end{array}$ & $\begin{array}{l}\mathrm{D} \\
1 \\
0\end{array}$ & $\begin{array}{c}E \\
29 \\
0\end{array}$ & $\begin{array}{l}\mathrm{F} \\
7 \\
0\end{array}$ & $\begin{array}{c}\mathrm{B} \\
18 \\
1.82\end{array}$ & $\begin{array}{c}E \\
82 \\
0\end{array}$ & $\begin{array}{c}\text { A } \\
33 \\
1\end{array}$ & $\begin{array}{c}\mathrm{B} \\
0 \\
1.82\end{array}$ & $\begin{array}{c}\mathrm{C} \\
0 \\
1.54\end{array}$ & $\begin{array}{c}\mathrm{D} \\
33 \\
0\end{array}$ & $\begin{array}{l}\mathrm{E} \\
0 \\
0\end{array}$ & $\begin{array}{c}\mathrm{F} \\
34 \\
0\end{array}$ & $\begin{array}{c}\mathrm{C} \\
0 \\
1.54\end{array}$ & $\begin{array}{c}\mathrm{F} \\
100 \\
0\end{array}$ & $\begin{array}{l}\text { A } \\
0 \\
1\end{array}$ & $\begin{array}{c}\mathrm{B} \\
0 \\
1.82\end{array}$ & $\begin{array}{c}\mathrm{C} \\
0 \\
1.54\end{array}$ & $\begin{array}{l}\mathrm{D} \\
0 \\
0\end{array}$ & $\begin{array}{l}\mathrm{E} \\
0 \\
0\end{array}$ & $\begin{array}{l}\mathrm{F} \\
0 \\
0\end{array}$ \\
\hline (8) Expected pay-off (\$) & \multicolumn{6}{|c|}{0.66} & \multicolumn{8}{|c|}{0.32} & \multicolumn{8}{|c|}{0} \\
\hline $\begin{array}{l}\text { Proposer }=35 \\
\text { (1) Proposed Coalition } \\
\text { (2) Percentage of Total Proposals } \\
\text { (3) Outcome of Response } \\
\text { (4) Outcome by Percentage }\end{array}$ & \multicolumn{6}{|c|}{$\begin{array}{c}\{20,35,45\} \\
23 \\
\text { Pass } \\
100\end{array}$} & \multicolumn{8}{|c|}{$\begin{array}{c}\{20,35\} \\
73\end{array}$} & \multicolumn{8}{|c|}{$\begin{array}{c}\{35,45\} \\
4\end{array}$} \\
\hline $\begin{array}{l}\text { (5) Final Coalition (see Note) } \\
\text { (6) Frequency (Percentage) } \\
\text { (7) Final pay-off (\$) }\end{array}$ & $\begin{array}{c}\mathrm{A} \\
55 \\
1.75\end{array}$ & $\begin{array}{c}\text { B } \\
0 \\
3.18\end{array}$ & $\begin{array}{l}\mathrm{C} \\
5 \\
0\end{array}$ & $\begin{array}{c}\mathrm{D} \\
0 \\
2.19\end{array}$ & $\begin{array}{c}E \\
13 \\
5\end{array}$ & $\begin{array}{c}\mathrm{F} \\
27 \\
0\end{array}$ & $\begin{array}{c}\mathrm{B} \\
39 \\
3.18\end{array}$ & $\begin{array}{l}E \\
61 \\
5\end{array}$ & $\begin{array}{c}\mathrm{A} \\
72 \\
1.75\end{array}$ & $\begin{array}{c}\text { B } \\
0 \\
3.18\end{array}$ & $\begin{array}{l}\mathrm{C} \\
0 \\
0\end{array}$ & $\begin{array}{c}\mathrm{D} \\
4 \\
2.19\end{array}$ & $\begin{array}{l}\text { E } \\
9 \\
5\end{array}$ & $\begin{array}{c}\mathrm{F} \\
15 \\
0\end{array}$ & $\begin{array}{c}\mathrm{D} \\
0 \\
2.19\end{array}$ & $\begin{array}{c}\mathrm{F} \\
100 \\
0\end{array}$ & $\begin{array}{c}\mathrm{A} \\
0 \\
1.75\end{array}$ & $\begin{array}{l}\text { B } \\
0 \\
3.18\end{array}$ & $\begin{array}{l}\mathrm{C} \\
0 \\
0\end{array}$ & $\begin{array}{c}\mathrm{D} \\
0 \\
2.19\end{array}$ & $\begin{array}{l}\mathrm{E} \\
0 \\
5\end{array}$ & $\begin{array}{c}\mathrm{F} \\
100 \\
0\end{array}$ \\
\hline (8) Expected pay-off (\$) & \multicolumn{6}{|c|}{1.63} & \multicolumn{8}{|c|}{2.61} & \multicolumn{8}{|c|}{0} \\
\hline $\begin{array}{l}\text { Proposer = 45 } \\
\text { (1) Proposed Coalition } \\
\text { (2) Percentage of Total Proposals } \\
\text { (3) Outcome of Response } \\
\text { (4) Outcome by Percentage }\end{array}$ & \multicolumn{6}{|c|}{$\begin{array}{c}\{20,35,45\} \\
43 \\
\text { Pass } \\
100 \\
\end{array}$} & \multicolumn{8}{|c|}{$\begin{array}{c}\{20,45\} \\
31\end{array}$} & \multicolumn{8}{|c|}{$\begin{array}{c}\{35,45\} \\
26\end{array}$} \\
\hline $\begin{array}{l}\text { (5) Final Coalition (see Note) } \\
\text { (6) Frequency (Percentage) } \\
\text { (7) Final pay-off (\$) }\end{array}$ & $\begin{array}{c}\mathrm{A} \\
54 \\
2.25\end{array}$ & $\begin{array}{l}\text { B } \\
0 \\
0\end{array}$ & $\begin{array}{c}C \\
0 \\
3.46\end{array}$ & $\begin{array}{c}\mathrm{D} \\
0 \\
2.81\end{array}$ & $\begin{array}{c}E \\
37 \\
0\end{array}$ & $\begin{array}{l}F \\
9 \\
5\end{array}$ & $\begin{array}{c}C \\
60 \\
3.46\end{array}$ & $\begin{array}{l}\mathrm{F} \\
40 \\
5\end{array}$ & $\begin{array}{c}\text { A } \\
33 \\
2.25\end{array}$ & $\begin{array}{l}\text { B } \\
7 \\
0\end{array}$ & $\begin{array}{c}\mathrm{C} \\
0 \\
3.46\end{array}$ & $\begin{array}{c}\mathrm{D} \\
0 \\
2.81\end{array}$ & $\begin{array}{c}E \\
53 \\
0\end{array}$ & $\begin{array}{l}\mathrm{F} \\
7 \\
5\end{array}$ & $\begin{array}{c}\mathrm{D} \\
0 \\
2.81\end{array}$ & $\begin{array}{c}\mathrm{F} \\
100 \\
5\end{array}$ & $\begin{array}{c}\text { A } \\
34 \\
2.25\end{array}$ & $\begin{array}{c}\mathrm{B} \\
13 \\
0\end{array}$ & $\begin{array}{c}C \\
0 \\
3.46\end{array}$ & $\begin{array}{c}\mathrm{D} \\
0 \\
2.81\end{array}$ & $\begin{array}{c}\mathrm{E} \\
40 \\
0\end{array}$ & $\begin{array}{c}\mathrm{F} \\
13 \\
5\end{array}$ \\
\hline (8) Expected pay-off (\$) & \multicolumn{6}{|c|}{1.65} & \multicolumn{8}{|c|}{2.28} & \multicolumn{8}{|c|}{2.44} \\
\hline
\end{tabular}

Note: Final Coalitions labels are $A=\{20,35,45\}, B=\{20,35\}, C=\{20,45\}, D=\{35,45\}, E=\{35\}$, and $F=\{45\}$. See the text for an explanation of each of the rows. Note: These are the proposals made in the first round of every game. 


\section{Appendix C. Probability of Proposal and Response Strategies}

To assess the probability of proposing the grand coalition, we employ a logit analysis that takes into account an agent's power as well as several possible scenarios relating to immediate past experience. These experience variables are: (1) Agents have no prior experience in proposing a coalition when currently chosen to be a proposer; (2) they proposed a two-person coalition the last time the agent was chosen to be a proposer and being in the final coalition that formed at that time; (3) they proposed a two-person coalition the last time the agent was chosen to be a proposer but were out of the final coalition that formed at that time; (4) they proposed the grand coalition the last time the agent was chosen to be a proposer and were in final coalition that formed at that time; and (5) they proposed the grand coalition the last time the agent was chosen to be a proposer but were out of the final coalition that formed at that time.

We ran five specifications: (1) With just the agents' power as controls; (2) with an interaction of power and late games; (3) with just prior experience as controls; (4) both power and experience as controls; and (5) power, experience, stakes, and late game interactions as controls.

Table A4 provides corroborating evidence on the analysis we presented earlier. First, agents with relatively higher power (i.e., Agents 35 and 45) have a lower probability of proposing the grand coalition, and this result is robust throughout all specifications. Another robust finding is that when an agent proposes the grand coalition when he was last a proposer, he will more likely propose the grand coalition if chosen as a proposer again. This is shown by the positive and statistically significant coefficients on the "Proposed grand, in final" variable throughout all specifications. The interaction with late games shows up positive and significant, thereby echoing our prior result that more grand coalitions are proposed during late games.

Table A4. Probability of proposing the grand coalition.

\begin{tabular}{|c|c|c|c|c|c|}
\hline & \multicolumn{5}{|c|}{ Dependent Variable: } \\
\hline & \multicolumn{5}{|c|}{ Grand Coalition Proposed = 1} \\
\hline & (1) & (2) & (3) & (4) & (5) \\
\hline Power $=35$ & $\begin{array}{l}-1.743^{* * *} \\
(0.249)\end{array}$ & $\begin{array}{l}-1.194^{* * *} \\
(0.200)\end{array}$ & & $\begin{array}{l}-1.961 * * * \\
(0.239)\end{array}$ & $\begin{array}{l}-1.259 * * * \\
(0.194)\end{array}$ \\
\hline Power $=45$ & $\begin{array}{l}-1.102 * * * \\
(0.281)\end{array}$ & $\begin{array}{l}-0.769^{* * *} \\
(0.236)\end{array}$ & & $\begin{array}{l}-1.272^{* * *} \\
(0.256)\end{array}$ & $\begin{array}{l}-0.800 * * * \\
(0.219)\end{array}$ \\
\hline Late games & & $\begin{array}{c}1.512 * * * \\
(0.377)\end{array}$ & & & $\begin{array}{c}1.973 * * * \\
(0.431)\end{array}$ \\
\hline Power $=35 \times$ Late games & & $\begin{array}{l}-1.160 * * * \\
(0.438)\end{array}$ & & & $\begin{array}{l}-1.482 * * * \\
(0.567)\end{array}$ \\
\hline Power $=45 \times$ Late games & & $\begin{array}{l}-0.659 \\
(0.487)\end{array}$ & & & $\begin{array}{l}-0.943^{* *} \\
(0.382)\end{array}$ \\
\hline Proposed two-person, in final & & & $\begin{array}{c}0.236 \\
(0.308)\end{array}$ & $\begin{array}{c}0.362 \\
(0.344)\end{array}$ & $\begin{array}{c}0.120 \\
(0.417)\end{array}$ \\
\hline Proposed two-person, out of final & & & $\begin{array}{c}0.277 \\
(0.256)\end{array}$ & $\begin{array}{c}0.271 \\
(0.309)\end{array}$ & $\begin{array}{c}0.268 \\
(0.513)\end{array}$ \\
\hline Proposed grand, in final & & & $\begin{array}{c}1.517 * * * \\
(0.184)\end{array}$ & $\begin{array}{c}1.865^{* * *} \\
(0.196)\end{array}$ & $\begin{array}{c}1.667 * * * \\
(0.494)\end{array}$ \\
\hline Proposed grand, out of final & & & $\begin{array}{c}1.327 * * * \\
(0.297)\end{array}$ & $\begin{array}{c}1.483^{* * *} \\
(0.346)\end{array}$ & $\begin{array}{c}0.830 \\
(0.514)\end{array}$ \\
\hline$\$ 5$ stake & & & & & $\begin{array}{c}0.044 \\
(0.427)\end{array}$ \\
\hline$\$ 20$ stake & & & & & $\begin{array}{c}0.744 \\
(0.475)\end{array}$ \\
\hline$\$ 50$ stake & & & & & $\begin{array}{l}1.215^{* *} \\
(0.489)\end{array}$ \\
\hline
\end{tabular}


Table A4. Cont.

\begin{tabular}{lccccc}
\hline & \multicolumn{5}{c}{ Dependent Variable: } \\
\cline { 2 - 6 } & \multicolumn{5}{c}{ Grand Coalition Proposed = 1 } \\
\cline { 2 - 6 } & $\mathbf{( 1 )}$ & $\mathbf{( 2 )}$ & $\mathbf{( 3 )}$ & $\mathbf{( 4 )}$ & $\mathbf{( 5 )}$ \\
\hline Constant & $0.392^{* *}$ & $-0.357^{*}$ & $-1.019^{* * *}$ & -0.134 & $-0.606^{* *}$ \\
& $(0.179)$ & $(0.198)$ & $(0.222)$ & $(0.277)$ & $(0.290)$ \\
\hline Experience/Late Game Interaction & No & No & No & No & Yes \\
\hline Observations & 535 & 535 & 535 & 535 & 535 \\
Log Likelihood & -324.462 & -308.903 & -334.516 & -299.883 & -287.569 \\
Akaike Inf. Crit. & 654.923 & 629.806 & 679.032 & 613.766 & 609.137 \\
\hline
\end{tabular}

Note: ${ }^{*} p<0.1{ }^{* *} p<0.05 ;{ }^{* * *} p<0.01$. Standard errors in parentheses are clustered at the session level $(11$ session clusters). The units of observation are group games (see Table 1). Base categories for stakes are the games before the last game of the sessions.

We likewise performed a similar analysis with response strategies. We first examined the probability of accepting the grand coalition, conditional on being proposed a grand coalition. In these runs we also account for immediate past experience in responding to a proposed coalition. These possible scenarios are: (1) Agents have no prior experience in responding when currently chosen to be a responder; (2) accepting a two-person coalition the last time an agent was chosen to be a responder and being in the final coalition that formed at that time; (3) accepting a two-person coalition the last time that an agent was chosen to be a responder but being out of the final coalition that formed at that time; (4) rejecting a two-person coalition the last time that an agent was chosen to be a responder and being in the final coalition that formed at that time; (5) rejecting a two-person coalition the last time that an agent was chosen to be a responder but being out of the final coalition that formed at that time; (6) accepting the grand coalition the last time that an agent was chosen to be a responder and being in the final coalition that formed at that time; (7) accepting the grand coalition the last time that an agent was chosen to be a responder but being out of the final coalition that formed at that time; (8) rejecting the grand coalition the last time that an agent was chosen to be a responder and being in the final coalition that formed at that time; and (9) rejecting the grand coalition the last time that an agent was chosen to be a responder but being out of the final coalition that formed at that time.

The first specification in Table A5 illustrates that the negative coefficients for Agents 35 (significant) and 45 (not significant) reflect their reluctance to accept a grand coalition compared with Agent 20 . The experience variables do not seem to be robust, but some results are worth mentioning. First, the "Accept 2 person-out" may signify that an agent may be willing to take the risk of being in a two-person coalition for the chance of a higher pay-off. Second, the "Reject grand, in" decreases the probability of accepting the grand coalition, suggesting a form of hysteresis in the response strategies.

Finally, we examine the probability that the agents will accept a two-person coalition, conditional on being proposed a two-person coalition. We likewise control for the same experience variables as in the case where we analyzed the probability of accepting the grand coalition. The difference here is that we split the agent with power 35 into two scenarios, one when offered the coalition $\{20,35\}$ and the other when offered the coalition $\{35,45\}$, to account for the possible differences in strategies when faced with these different coalitions. In Table A6, we see that drawing a higher power robustly increases the probability that agents will accept a two-person coalition. This effect is particularly strong for Agent 45, since he can always propose to be a dictator once a two-person coalition that includes him forms. For Agent 35, the tendency to accept a two-person coalition is strong only when facing a $\{20,35\}$ proposal. The other robust variable shows that rejecting the grand coalition the last time he was a responder makes an agent increase his probability that a two-person coalition will be accepted. This also suggests some consistency and hysteresis in the behavior of these agents. 
Table A5. Probability of accepting a grand coalition.

\begin{tabular}{|c|c|c|c|c|c|}
\hline & \multicolumn{5}{|c|}{ Dep. Variable: Accepting the Grand Coalition $=1$} \\
\hline & (1) & (2) & (3) & (4) & (5) \\
\hline Power $=35$ & $\begin{array}{c}-1.686^{* *} \\
(0.745)\end{array}$ & $\begin{array}{c}-1.896^{*} \\
(0.998)\end{array}$ & & $\begin{array}{c}-1.609^{* *} \\
(0.801)\end{array}$ & $\begin{array}{c}-2.459 * * \\
(1.124)\end{array}$ \\
\hline Power $=45$ & $\begin{array}{l}-0.715 \\
(0.768)\end{array}$ & $\begin{array}{c}0.260 \\
(0.161)\end{array}$ & & $\begin{array}{l}-0.585 \\
(0.863)\end{array}$ & $\begin{array}{c}0.179 \\
(0.280)\end{array}$ \\
\hline Late games & & $\begin{array}{l}-0.297 \\
(0.784)\end{array}$ & & & $\begin{array}{c}15.787^{* * *} \\
(1.386)\end{array}$ \\
\hline Power $=35 \times$ Late games & & $\begin{array}{c}0.331 \\
(0.838)\end{array}$ & & & $\begin{array}{c}1.164 \\
(1.073)\end{array}$ \\
\hline Power $=45 \times$ Late games & & $\begin{array}{l}-1.188 \\
(0.896)\end{array}$ & & & $\begin{array}{l}-0.653 \\
(0.899)\end{array}$ \\
\hline Accept two-person, in final & & & $\begin{array}{l}-1.386 \\
(0.959)\end{array}$ & $\begin{array}{l}-1.259 \\
(1.036)\end{array}$ & $\begin{array}{l}-1.559 \\
(1.233)\end{array}$ \\
\hline Accept two-person, out of final & & & $\begin{array}{c}-2.079 * * \\
(0.821)\end{array}$ & $\begin{array}{c}-1.906 \text { ** } \\
(0.931)\end{array}$ & $\begin{array}{l}-0.831 \\
(1.217)\end{array}$ \\
\hline Reject two-person, in final & & & $\begin{array}{l}-1.144 \\
(0.912)\end{array}$ & $\begin{array}{l}-1.107 \\
(0.934)\end{array}$ & $\begin{array}{l}-1.827 \\
(1.221)\end{array}$ \\
\hline Reject two-person, out of final & & & $\begin{array}{l}-1.553 \\
(1.048)\end{array}$ & $\begin{array}{l}-1.653 \\
(1.025)\end{array}$ & $\begin{array}{c}16.662 * * * \\
(0.712)\end{array}$ \\
\hline Accept grand, in final & & & $\begin{array}{c}1.602 \\
(1.250)\end{array}$ & $\begin{array}{c}1.684 \\
(1.321)\end{array}$ & $\begin{array}{c}16.603 * * * \\
(0.871)\end{array}$ \\
\hline Accept grand, out of final & & & $\begin{array}{l}-0.907 \\
(0.658)\end{array}$ & $\begin{array}{l}-0.763 \\
(0.705)\end{array}$ & $\begin{array}{c}16.574^{* * *} \\
(1.134)\end{array}$ \\
\hline Reject grand, in final & & & $\begin{array}{c}-3.104^{* * *} \\
(0.938)\end{array}$ & $\begin{array}{c}-3.080 * * * \\
(0.964)\end{array}$ & $\begin{array}{l}-2.953 \\
(2.775)\end{array}$ \\
\hline Reject grand, out of final & & & $\begin{array}{l}-1.649 \\
(1.377)\end{array}$ & $\begin{array}{l}-1.480 \\
(1.323)\end{array}$ & $\begin{array}{c}17.440 \text { *** } \\
(2.022)\end{array}$ \\
\hline$\$ 5$ stake & & & & & $\begin{array}{c}17.569^{* * *} \\
(1.150)\end{array}$ \\
\hline$\$ 20$ stake & & & & & $\begin{array}{c}18.185^{* * *} \\
(1.222)\end{array}$ \\
\hline$\$ 50$ stake & & & & & $\begin{array}{c}0.804 \\
(1.351)\end{array}$ \\
\hline Constant & $\begin{array}{c}3.423 * * * \\
(0.675)\end{array}$ & $\begin{array}{c}3.611^{* * *} \\
(0.945)\end{array}$ & $\begin{array}{c}3.258 * * * \\
(0.666)\end{array}$ & $\begin{array}{c}4.220 * * * \\
(0.846)\end{array}$ & $\begin{array}{c}4.584^{* * *} \\
(1.179)\end{array}$ \\
\hline Experience/Late Game Interaction & No & No & No & No & Yes \\
\hline $\begin{array}{l}\text { Observations } \\
\text { Log Likelihood } \\
\text { Akaike Inf. Crit. }\end{array}$ & $\begin{array}{c}406 \\
-117.490 \\
240.979\end{array}$ & $\begin{array}{c}406 \\
-116.122 \\
244.243\end{array}$ & $\begin{array}{c}406 \\
-103.694 \\
225.387\end{array}$ & $\begin{array}{c}406 \\
-98.239 \\
218.477\end{array}$ & $\begin{array}{c}406 \\
-87.699 \\
225.398\end{array}$ \\
\hline
\end{tabular}

Note: $* p<0.1 ; * * p<0.05 ; * * * p<0.01$. Standard errors in parentheses are clustered at the session level (11 session-clusters). The units of observation are group games (see Table 1). Base categories for stakes are the games before the last game of the sessions.

Table A6. Probability of accepting a two-person coalition.

\begin{tabular}{|c|c|c|c|c|c|}
\hline & \multicolumn{5}{|c|}{ Dep. Variable: Accepting Two-Person Coalition = 1} \\
\hline & (1) & (2) & (3) & (4) & (5) \\
\hline Power $=35,\{20,35\}$ & $\begin{array}{c}2.876^{* * *} \\
(0.727)\end{array}$ & $\begin{array}{c}3.297 * * * \\
(0.860)\end{array}$ & & $\begin{array}{c}2.963 * * * \\
(0.794)\end{array}$ & $\begin{array}{c}3.341^{* * *} \\
(0.934)\end{array}$ \\
\hline Power $=35,\{35,45\}$ & $\begin{array}{l}-0.141 \\
(0.290)\end{array}$ & $\begin{array}{l}-0.048 \\
(0.505)\end{array}$ & & $\begin{array}{l}-0.178 \\
(0.282)\end{array}$ & $\begin{array}{l}-0.041 \\
(0.576)\end{array}$ \\
\hline Power $=45$ & $\begin{array}{c}18.026^{* * * *} \\
(0.463)\end{array}$ & $\begin{array}{c}17.893^{* * * *} \\
(0.479)\end{array}$ & & $\begin{array}{c}18.044^{* * * *} \\
(0.473)\end{array}$ & $\begin{array}{c}18.004^{* * *} \\
(0.467)\end{array}$ \\
\hline Late games & & $\begin{array}{l}-0.288 \\
(0.360)\end{array}$ & & & $\begin{array}{c}0.451 \\
(1.255)\end{array}$ \\
\hline Power $=35,\{20,35\} \times$ Late games & & $\begin{array}{l}-0.948 \\
(0.982)\end{array}$ & & & $\begin{array}{l}-0.596 \\
(1.159)\end{array}$ \\
\hline Power $=35,\{35,45\} \times$ Late games & & $\begin{array}{l}-0.254 \\
(0.928)\end{array}$ & & & $\begin{array}{l}-0.470 \\
(0.956)\end{array}$ \\
\hline Power $=45 \times$ Late games & & $\begin{array}{c}0.288 \\
(0.773)\end{array}$ & & & $\begin{array}{l}-0.261 \\
(0.663)\end{array}$ \\
\hline
\end{tabular}


Table A6. Cont.

\begin{tabular}{|c|c|c|c|c|c|}
\hline & \multicolumn{5}{|c|}{ Dep. Variable: Accepting Two-Person Coalition = 1} \\
\hline & (1) & (2) & (3) & (4) & (5) \\
\hline Accept two-person, in final & & & $\begin{array}{l}-0.285 \\
(0.311)\end{array}$ & $\begin{array}{l}-0.311 \\
(0.328)\end{array}$ & $\begin{array}{l}-0.319 \\
(0.467)\end{array}$ \\
\hline Accept two-person, out of final & & & $\begin{array}{l}-0.144 \\
(0.271)\end{array}$ & $\begin{array}{c}0.165 \\
(0.334)\end{array}$ & $\begin{array}{l}-0.057 \\
(0.401)\end{array}$ \\
\hline Reject two-person, in final & & & $\begin{array}{c}-1.534^{* * *} \\
(0.379)\end{array}$ & $\begin{array}{c}-1.724^{* * *} \\
(0.455)\end{array}$ & $\begin{array}{l}-1.185 \\
(0.745)\end{array}$ \\
\hline Reject two-person, out of final & & & $\begin{array}{c}-0.818^{*} \\
(0.457)\end{array}$ & $\begin{array}{c}-0.755 * \\
(0.446)\end{array}$ & $\begin{array}{l}-0.838 \\
(1.018)\end{array}$ \\
\hline Accept grand, in final & & & $\begin{array}{c}-0.814^{* * *} \\
(0.258)\end{array}$ & $\begin{array}{c}-0.660 * * * \\
(0.200)\end{array}$ & $\begin{array}{l}-0.558 \\
(0.403)\end{array}$ \\
\hline Accept grand, out of final & & & $\begin{array}{c}-0.859 * * \\
(0.338)\end{array}$ & $\begin{array}{c}-0.534^{* *} \\
(0.239)\end{array}$ & $\begin{array}{l}-0.376 \\
(0.574)\end{array}$ \\
\hline Reject grand, in final & & & $\begin{array}{l}-0.076 \\
(0.715)\end{array}$ & $\begin{array}{l}-0.056 \\
(0.773)\end{array}$ & $\begin{array}{c}0.141 \\
(1.410)\end{array}$ \\
\hline Reject grand, out of final & & & $\begin{array}{c}13.930 * * * \\
(0.688)\end{array}$ & $\begin{array}{c}17.575^{* * *} \\
(0.718)\end{array}$ & $\begin{array}{c}17.173^{* * *} \\
(1.337)\end{array}$ \\
\hline$\$ 5$ stake & & & & & $\begin{array}{c}-1.488^{* * *} \\
(0.529)\end{array}$ \\
\hline$\$ 20$ stake & & & & & $\begin{array}{l}-0.781 \\
(1.680)\end{array}$ \\
\hline$\$ 50$ stake & & & & & $\begin{array}{c}0.691 \\
(0.643)\end{array}$ \\
\hline Constant & $\begin{array}{c}-0.460 * * \\
(0.203)\end{array}$ & $\begin{array}{c}-0.327 * \\
(0.184)\end{array}$ & $\begin{array}{c}0.636^{* * *} \\
(0.195)\end{array}$ & $\begin{array}{l}-0.009 \\
(0.190)\end{array}$ & $\begin{array}{l}-0.058 \\
(0.196)\end{array}$ \\
\hline Experience/Late Game Interaction & No & No & No & No & Yes \\
\hline $\begin{array}{l}\text { Observations } \\
\text { Log Likelihood } \\
\text { Akaike Inf. Crit. }\end{array}$ & $\begin{array}{c}332 \\
-181.300 \\
370.600\end{array}$ & $\begin{array}{c}332 \\
-179.578 \\
375.157\end{array}$ & $\begin{array}{c}332 \\
-218.975 \\
455.949\end{array}$ & $\begin{array}{c}332 \\
-171.540 \\
367.080\end{array}$ & $\begin{array}{c}332 \\
-170.199 \\
384.398\end{array}$ \\
\hline
\end{tabular}

Note: $* p<0.1 ;{ }^{* *} p<0.05 ;{ }^{* *} p<0.01$. Standard errors in parentheses are clustered at the session level (11 session-clusters). The units of observation are group games (see Table 1). Base categories for stakes are the games before the last game of the sessions.

\section{References}

1. Ray, D. A Game-Theoretic Perspective on Coalition Formation; Oxford University Press: New York, NY, USA, 2007.

2. Bueno de Mesquita, B.; Smith, A.; Siverson, R.; Morrow, J. The Logic of Political Surival; MIT Press: Cambridge, MA, USA, 2003.

3. Tullock, G. Autocracy; Kluwer Academic Publishers: Dorderecht, The Netherlands, 1987.

4. Acemoglu, D.; Egorov, G.; Sonin, K. Coalition Formation in Non-Democracies. Rev. Econ. Stud. 2008, 75, 987-1009. [CrossRef]

5. Ward, A.; Bishop, K.; Sonnenfeld, J. Pyrrhic Victories: The Cost to the Board of Ousting the CEO. J. Organ. Behav. 1999, 20, 767-781. [CrossRef]

6. Bogomolnaia, A.; Jackson, M. The Stability of Hedonic Coalition Structures. Games Econ. Behav. 2002, 38, 201-230. [CrossRef]

7. Ehlers, L. Coalitional Strategy-proof House Allocation. J. Econ. Theory 2002, 105, 298-317. [CrossRef]

8. Juarez, R. Group Strategyproof Cost Sharing: The Role of Indifferences. Games Econ. Behav. 2013, 82, $218-239$. [CrossRef]

9. Jandoc, K.; Juarez, R. Self-enforcing Coalitions with Power Accumulation. Int. J. Game Theory 2017, 42, 327-355. [CrossRef]

10. Frederick, S.; Loewenstein, G.; O’Donoghue, T. Time Discounting and Time Preference: A Critical Review. J. Econ. Lit. 2002, 40, 351-401. [CrossRef]

11. Gabaix, X.; Laibson, D. Myopia and Discounting; NBER Working Paper No. DP11914; National Bureau of Economic Research: Cambridge, MA, USA, 2017. 
12. LePine, J.; Erez, A.; Johnson, D. The Nature and Dimensionality of Organizational Citizenship Behavior: A Critical Review and Meta-Analysis. J. Appl. Psychol. 2002, 87, 52-65. [CrossRef]

13. Charness, G.; Rabin, M. Understanding Social Preferences with Simple Tests. Q. J. Econ. 2002, 117, 817-869. [CrossRef]

14. Gruning, C.; Peters, W. Can Justice and Fairness and Enlarge International Environmental Agreements? Games 2010, 1, 137-158. [CrossRef]

15. Horowitz, A. A Test of the Core, Bargaining Set, Kernel, and Shapley Models in n-person Quota Games with One Weak Player. Theory Decis. 1977, 8, 49-65. [CrossRef]

16. Rapoport, A.; Kahan, J. When Three is Not Always Two Against One: Coalitions in Experimental Three-person Cooperative Games. J. Exp. Soc. Psychol. 1976, 12, 253-273. [CrossRef]

17. Fiorina, M.; Plott, C. Committee Decisions under Majority Rule: An Experimental Study. Am. Political Sci. Rev. 1978, 72, 575-598. [CrossRef]

18. Baron, D.; Ferejohn, J. Bargaining in Legislatures. Am. Political Sci. Rev. 1989, 83, 1181-1206. [CrossRef]

19. McKelvey, R. An Experimental Test of a Stochastic Game Model of Committee Bargaining. In Laboratory Research in Political Economy; Palfrey, T., Ed.; University of Michigan Press: Ann Arbor, MI, USA, 1991.

20. Frechette, G.; Kagel, J.; Morelli, M. Nominal Bargaining Power, Selection Protocol, and Dicounting in Legislative Bargaining. J. Public Econ. 2005, 89, 1497-1517. [CrossRef]

21. Battaglini, M.; Palfrey, T. The Dynamics of Distributive Politics. Econ. Theory 2012, 49, 739-777. [CrossRef]

22. Nash, J.; Nagel, R.; Ockenfels, A.; Selten, R. The Agencies Method for Coalition Formation in Experimental Games. Proc. Natl. Acad. Sci. USA 2012, 109, 20358-20363. [CrossRef]

23. Sanchez-Pages, S. Endogenous Coalition Formation in Contests. Rev. Econ. Des. 2007, 11, 139-163. [CrossRef]

24. Herbst, L.; Konrad, K.; Morath, F. Endogenous Group Formation in Experimental Contests. Eur. Econ. Rev. 2015, 74, 163-189. [CrossRef]

25. Dechenaux, E.; Kovenock, D.; Sheremeta, R. A Survey of Experimental Research on Contests, All-pay Auctions and Tournaments. Exp. Econ. 2015, 18, 609-669. [CrossRef]

26. Tremewan, J.; Vanberg, C. The Dynamics of Coalition Formation: A Multilateral Bargaining Experiment with Free Timing of Moves. J. Econ. Behav. Organ. 2016, 130, 33-46. [CrossRef]

27. Merida-Campos, C.; Willmott, S. The Effect of Heterogeneity on Coalition Formation in Iterated Request for Proposal Scenarios. In Proceedings of the Fourth European Workshop on Multi-Agent Systems (EUMAS 06), Lisbon, Portugal, 14-15 December 2006.

28. Chalkiadakis, G.; Boutilier, C. Sequentially Optimal Repeated Coalition Formation Under Uncertainty. Auton. Agents Multi-Agent Syst. 2012, 24, 441-484. [CrossRef]

29. Hyndman, K.; Ozbay, E.; Schotter, A.; Ehrblatt, W. Convergence: An Experimental Study of Teaching and Learning in Repeated Games. J. Eur. Econ. Assoc. 2012, 10, 573-604. [CrossRef]

30. Mengel, F. Learning by (Limited) Forward Looking Players. J. Econ. Behav. Organ. 2014, 108, 59-77. [CrossRef]

31. Harrison, G.; List, J. Field Experiments. J. Econ. Lit. 2004, 42, 1009-1055. [CrossRef]

32. Slonim, R.; Roth, A. Learning in High Stakes Ultimatum Games: An Experiment in the Slovak Republic. Econometrica 1998, 66, 569-596. [CrossRef]

33. Kachelmeier, S.; Shehata, M. Examining Risk Preferences Under High Monetary Incentives: Experimental Evidence from the Peoples Republic of China. Am. Econ. Rev. 1992, 82, 1120-1141.

34. Cameron, L. Raising the Stakes in the Ultimatum Game: Experimental Evidence from Indonesia. Econ. Inq. 1999, 37, 47-59. [CrossRef]

35. Greiner, B. Subject Pool Recruitment Procedures: Organizing Experiments with ORSEE. J. Econ. Sci. Assoc. 2015, 1, 114-125. [CrossRef]

36. Bolton, G.; Ockenfels, A. ERC: A Theory of Equity, Reciprocity and Competition. Am. Econ. Rev. 2000, 90, 166-193. [CrossRef]

37. Nagel, R.; Fang, T. Experimental Results on the Centipede Game in Normal Form: An Investigation on Learning. J. Math. Psychol. 1998, 42, 356-384. [CrossRef] 
38. Selten, R. Axiomatic Characterization of the Quadratic Scoring Rule. Exp. Econ. 1998, 1, 43-62. [CrossRef]

39. Jandoc, K.; Juarez, R. Forming Coalitions Under Sharing Disagreements; University of Hawaii: Honolulu, HI, USA, 2019.

(c)

(C) 2019 by the authors. Licensee MDPI, Basel, Switzerland. This article is an open access article distributed under the terms and conditions of the Creative Commons Attribution (CC BY) license (http:/ / creativecommons.org/licenses/by/4.0/). 